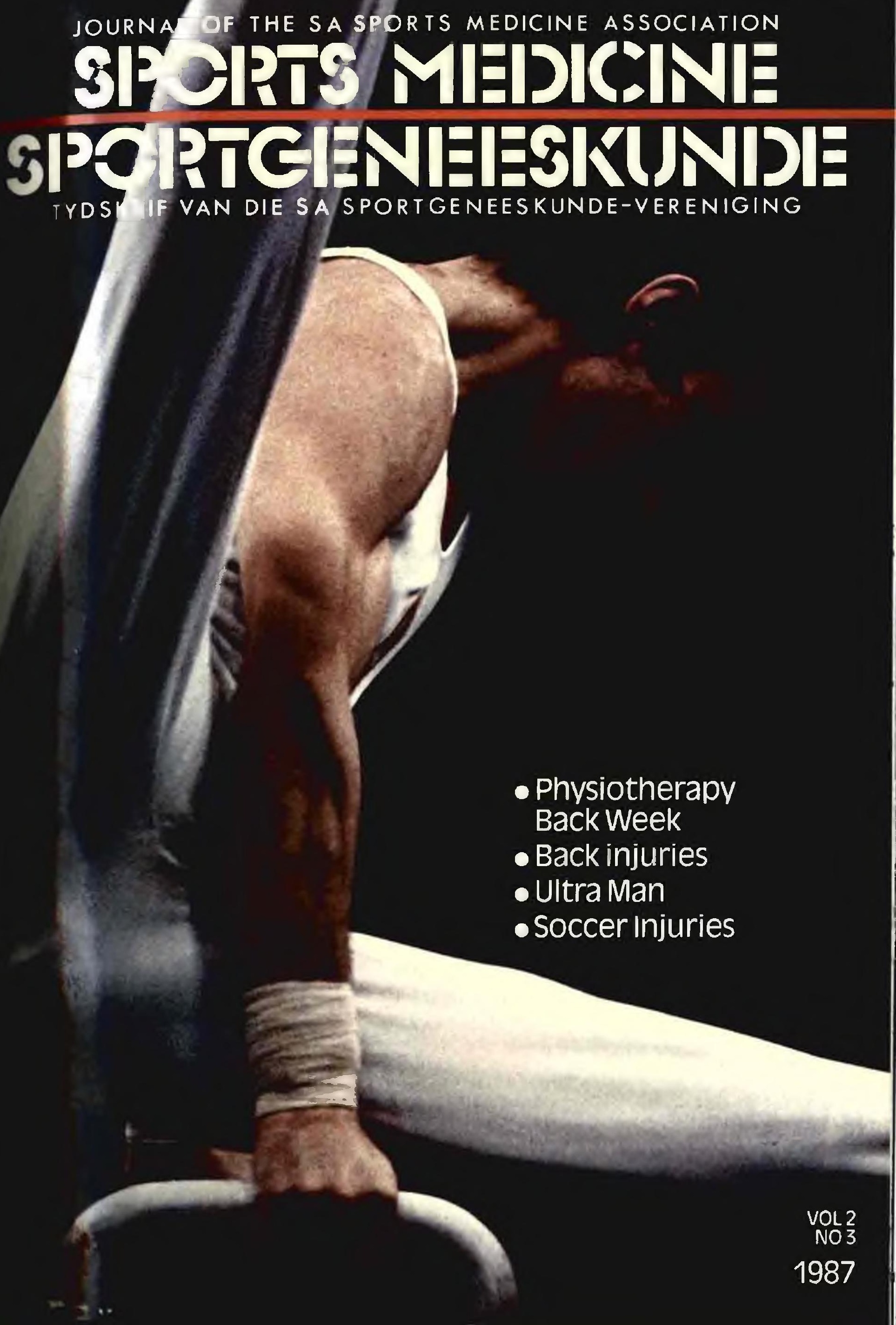


Reg. Mo./Mr. K/3.1/253 [53]

In sports injury and trauma.

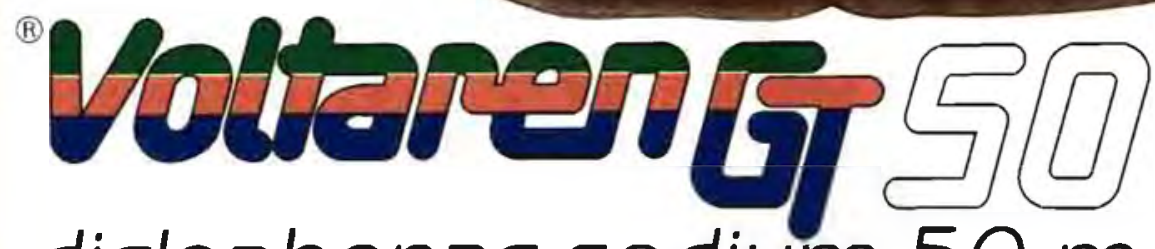


JOURNAL OF THE S.A.

SPORTS MEDICINE

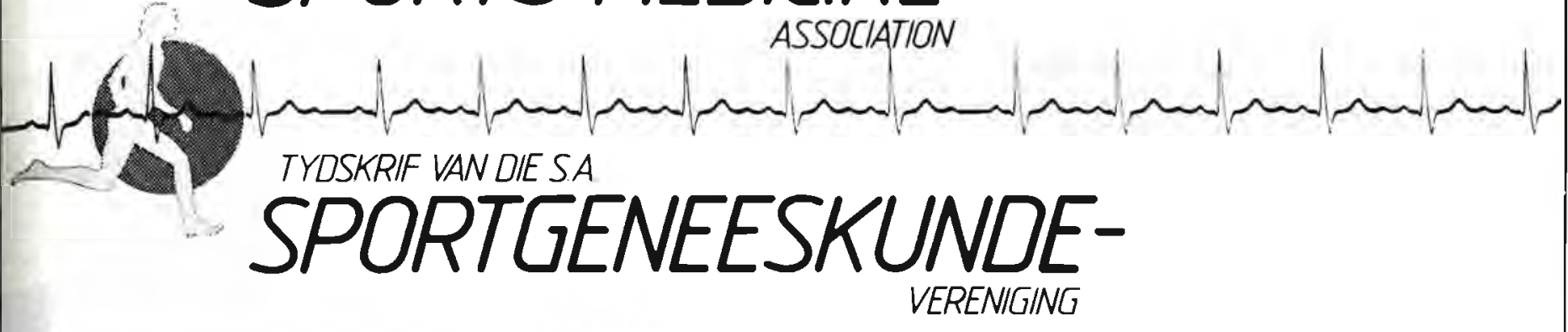

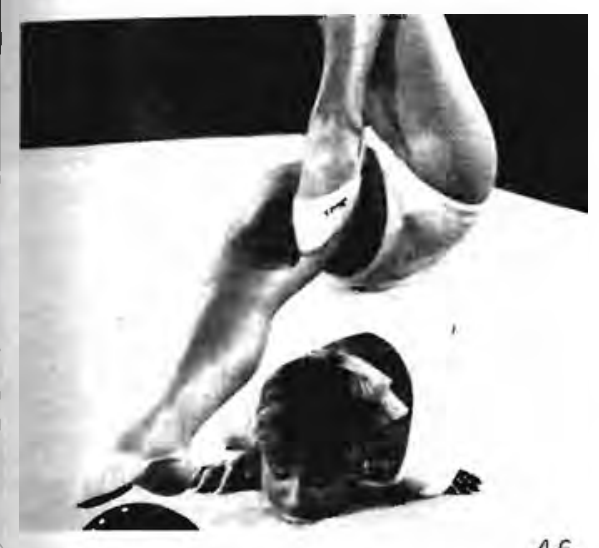

4.6
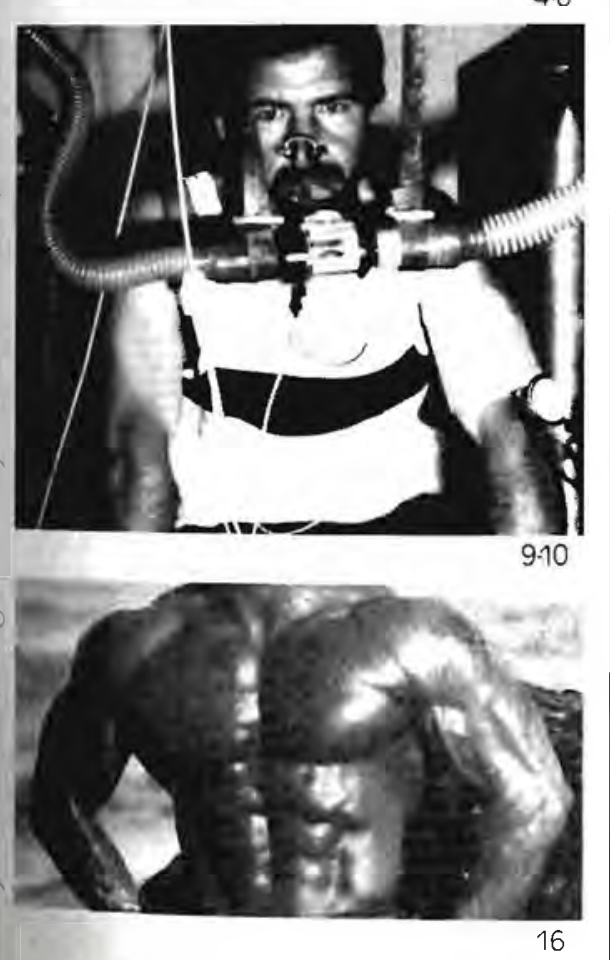

CIBA-GEIGY

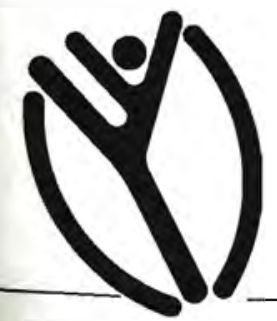

2 EDITORIAL COMMENT

Teaching of Sports Medicine

3 FEATURE

Back Week

4 FEATURE

Back Injuries in Gymnastics

7 PENSÉES

Sport and the Philosophy of Life

\section{ULTRA MAN}

Ultra Man put to Test

11 SASMANEWS

\section{FEATURE}

Soccer Injuries

16 ABSTRACTS

Bodybuilders' Psychosis

18 FEATURE

Memory Jogger

\section{FORUM}

Rugby Injuries and Tackle

20 NATIONAL SYMPOSIUM

Editor in ChiefDR CNOBLEMBBCh, FCS(SA) AssociateEditorsPROF T NOAKESMBChB,MD DR DAWIE VAN VELDEN MBChB (Stell) M PraXMed(Pretoria) Advisory Board MEDICINE. Dr I COHEN MB ChBD ObST, RCOC ORTHOPAEDIC TRAUMATOLOCY: DR P FIRER BSC (Eng) MB BCh (WIts) M Med (Ortho)(Wits) BRIC E HUCO MB ChB, MMed (Chir) Orthopaedics DR JC USDIN MB BCh, FRCS (Edın) CARDIOLOCY: COL DPMYBURGH SM MB ChB, FACC

PHYSICAL EDUCATION: HANNES BOTHA D Phil (Phys Ed) GYNAECOLOCY: DR JACK ADNO MB BCh (Wits) MD (Med) Dip O\&G (Wits)

Front Cover: Transparency courtesy of Image Bank The Journal of the SA Sports Medicine Association is exclusively sponsored by Ciba Geigy (Pty) Ltd. The journal is produced by Bates Hickman and Associates (Pty) Ltd. PO Box 783776, Sandton 2146 The views expressed in this publication are those of the authors and not necessarily those of the sponsors or publishers. 


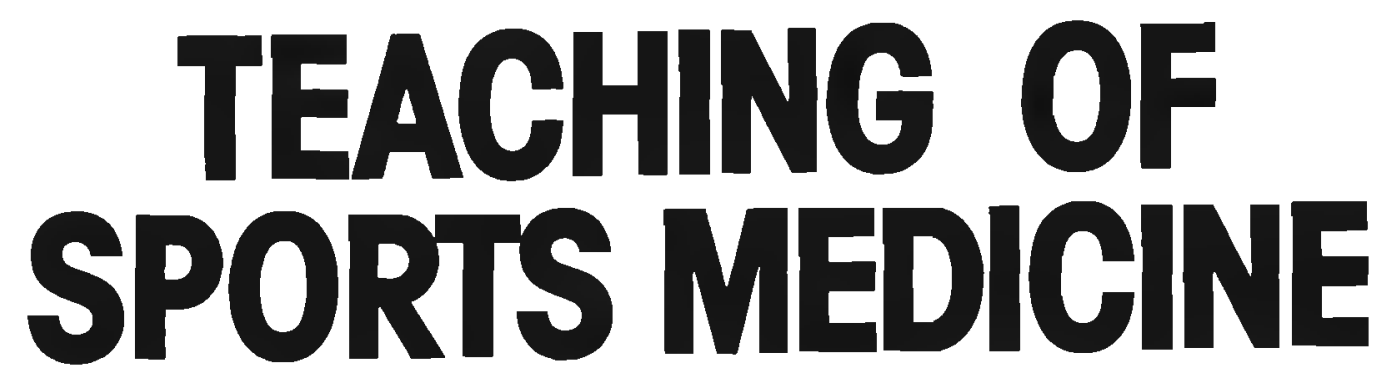

CLIVE NOBLE MBCHB.FCS (SA) Editor in Chief

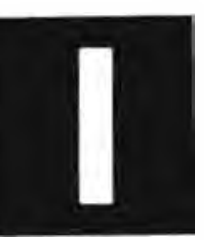

$n$ recent months I have been touring South Africa giving lectures on sports injuries. Unfortunately, I have often been appalled at the lack of knowledge of general practitioners as regards sports injuries and sports medicine in general. There are a few enthusiastic souls who have a positive interest but for the remainder of the doctors, the interest has been sadly lacking. The teaching of sports medicine in our universities has been kept to a minimum. There is no university, to my knowledge, that has a course in sports medicine or even a course in sports injuries, despite the fact that in private practice, a considerable number of injuries are seen. In many cases the sports injured patient and especially the runner, will seek alternative medicine rather than attend a general practitioner as they feel that the knowledge of the GP. is not sufficiently good and therefore the assess ment and handling of the injury has left the runner frustrated and because of the usual advice of rest for six weeks' untreated. Surely the time has come for our medical schools to introduce a course, albeit short, in sports medicine, taking in the various fields. Many sporting injuries are not specific to sport but particularly the overuse in juries are seen almost exclusively in sport. Bio-mechanics, as a subject, is almost excluded from university curriculae I do not think that it should be the task of sports medicine doctors to be teaching GP.s basic sports medicine. Updating of knowledge should be all that is required.

In this Journal we have a stimulating article on soccer injuries written under supervision by two medical students. Why can't there be more like this com. ing from our Universities? Let us hope that the future will see an emergence of sport medicine from our halls of learning.

\section{COMRADES MARATHON}

some time ago I queried what would happen if there were a large number of casualities in comrades. I also sug. gested that the qualifying time be reduced to reduce the numbers in the race. In the media it was reported that more than adequate facilities existed to cope with all emergencies and that there was no need to reduce the qualifying times. Well, this year the comrades organisers were put to the test The sight of runners lying on stretch. ers on the ground did not give one the impression of "adequate facilities". I am told that the Medics did a sterling job however, under trying circumstances. The excessive heat was obviously a major factor in creating the problems In the US.A. many races would be can celled with the temperatures ex. perienced during Comrades. I do not

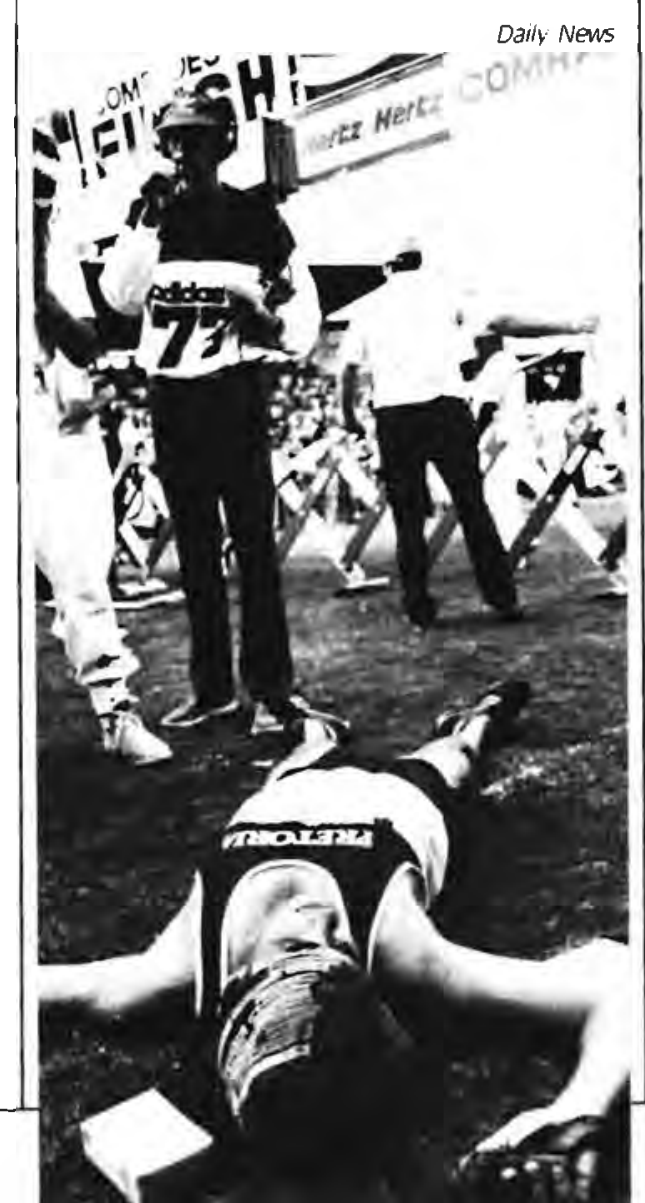

know the answer because cancelling comrades would have resulted in a riot the likes of which would have made the worst soccer violence pall into insignificance.

Possibly the doctors involved in Comrades treatment should have the power to take obviously ill or injured runners off the road.

\section{BACK INJURIES}

Back injuries in sport cover the whole spectrum of severity from the "niggIy" to the catastrophic. They often make diagnosis difficult and treatment even more so.

The catastrophic injuries, i.e., injuries causing paralysis are fortunately rare in controlled sporting situations. Diving into empty swimming pools and shallow streams with resulting neck injury and quadriplegia can only be prevented by public education. Neck injuries on the sports fields are largely associated with the high tackle in rugby and the collapsed scrum. Both of these are in the process of being eliminated with the high tackle being outlawed and experimental changes to the scrumming laws occurring.

some sports place tremendous loading forces on the spine with resultant injury. Gymnastics, squash and wrestling are such sports. Here rule changes will not result in a diminution of these injuries so from the medical point of view one has to be sure that the com. petitors have maximum musculo skeletal fitness in order to try and reduce injury possibilities.

Another problem facing sports doctors is the aging sportsman whose discs are already degenerating. Here even more carefully controlled exercises may be necessary in order to prevent injury. The old adage for example still applies one must be fit to play squash and not play squash to get fit!.

We wish the physiotherapists the best of luck in their National Back Week in september 1987.

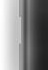




\section{FEATURE}

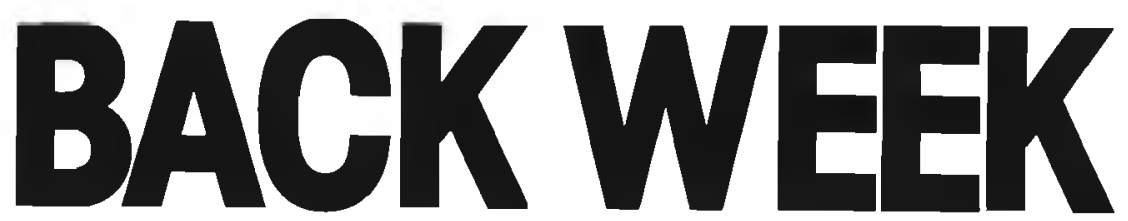

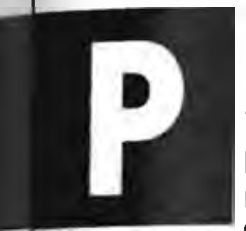

HYSIOTHERAPY BACK WEEK 1 6 SEPTEMBER 1987. Backache is one of the most common ailments seen by doctors and Physiotherapists it has been estimated that $80 \%$ of people suffer from significant backache at least once in their lives. Backache affects people's lives in all spheres and is a drain on the country's economy (See statistics)

Four years ago, the South African Society of Physiotherapy (SASP) declded that it was time to start educating the public on how to prevent and handle backache National Physiother. apy Back Week (NPBW) thus became an annual event in September

During NPBW, exhibitions at shopping centres educate the public not only on backache, but on the skill of physio therapists in dealing with the problem Physiotherapists have long ceased to function as "technicians" and are now ranked as full professionals in the term.

A four year B Sc course is now the standard qualification for physiotherapists Many physiotherapists then pro. ceed to specialist in the treatment of spinal problems.

Sponsors have assisted the SASP in producing posters, pamphiets and a nigh qualıty video on backache (Ciba Geigy!), all used during NP Back Week. The SABC, \& SATV has also given cover. age as well as many newspapers and magazines throughout the country. Feedback from the public has been ex. ceilent. There appears to be a great nunger for knowledge about backs The educational skills of the physio. therapists are, generally perhaps, not appreciated by medical practitioners who could prescribe it as readily as they prescribe anti-inflammatories Without adequate education, no back patient can be treated effectively, sur. gically or conservatively.

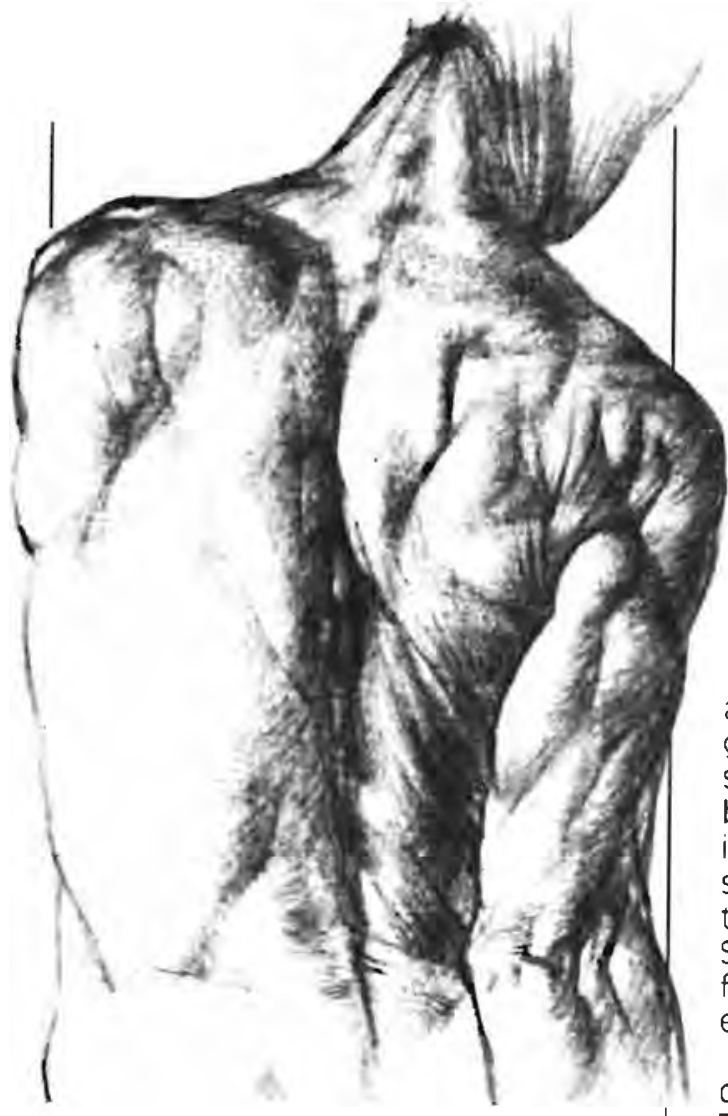

\section{STATISTICS OF BACK PAIN}

Onanygivendayinthe USA, 6.5 millionmen and women are in bed with low back trouble Backinjuriesare the majorindus. trial disabler 600000 workers are away from theirjobs during each year because they hurt their backs atwork. According to one estimate this costs their emplovers about a billion dollars annually in sick pay and in wages for replacement personnel. Among chronic conditions that limit the activities of Americans at home and at work, badback ratesthird - afterarthritis/ rheumatism and heart trouble.

Thereduction of $40.8 \%$ in manhourslost through education and the running of back schools hasbeen found to be the best wav to handle back trouble

in the UK in 1979, back pain cost British industry 18 millionlost working davscompared with 9.3 from strikes. It cost 18000 millionRandinlostproductionand cost the state 180 million Rand.

InSouth Africathestatisticsarevery hard to come by From Sanlam insurance com. pany one statistic is $59 \%$ of the claims in 1983 in the agegroup of $15-24$ yearswere fromback and neck problems in the male and $70 \%$ in the female.
The SASP have not limited themselves to NPBW only in their new venture: on going projects have been initiated and are worked on throughout the year, eg. the problem of undesirable exercises being given to schoolchildren. Members of the SASP are going out and educating the schools constantly, helping to modify these exercises and teach children to re. spect their spines, from the beginning Schools have/ also been given puppet shows and been involved in art and poster competitions. The official SASP NPBW poster is in

fact based on the winning entry from the Pretoria School for Music Art Ballet \& Drama. The art departments of UP and the Pretoria Technicons were also Involved in developing a logo for the SASP NPBW is an ambitious project with far reaching ideals. The SASP are to be congratulated on being the ones to tackle it and deserve the success it enjoys.

\section{Gillian Oosthuizen Curriculum Vitae} Dip Physio UOFS

Private practice, specialising in spınal rehabilitation. Read papers on the subject at three international Congresses. Lectures ballet students at the Pretoria Technicon and Pretoria school for Music, Art, Ballet \& Drama on body conditioning and injuries. Has been a consultant for various fitness organisations over the last five years. Closely involved with NPBW. (N) 


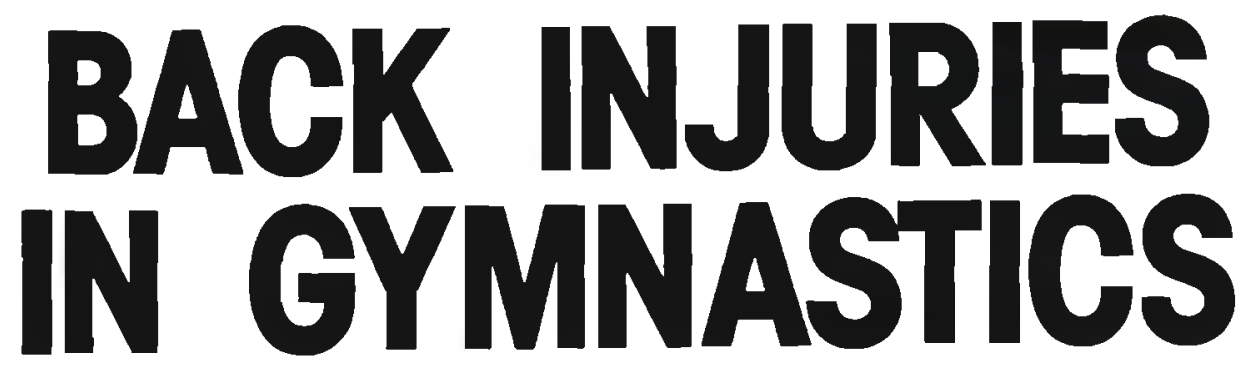

Lyle J. Micheli, M.D.

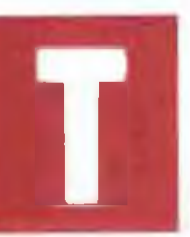

he stress placed by gym. nastics on the musculoskeletal system is well known, and disorders about the upper extremity - especially of the shoulder - and of the lower extremity - particularly the knee - certainly occur with great frequency. Another area of special concern in the young gymnast, however, is injury to the back and spine in the course of training and competing in this sport. The demands placed on the back, the lower back in particular, for both dramatic range of motion and a high level of strength in performing maneuvers and in absorbing shock of dismounts may well exceed that of any sport.

In association with such demands, the incidence of disorders of the spine in gymnasts appears to be high. ${ }^{235}$ This potential for back injury appears to result not only from single episodes of macrotrauma but also from the repeated microtrauma of hyperflexion, hyperextension, or twisting while performing gymnastic maneuvers.

Jackson et al. first noted an apparent increased incidence of spondylolysis in young female gymnasts when compared with a control population. ${ }^{5}$ They hypothesized that this was due to the repeated hyperextension of the spine occurring in gymnastics. Snook reported two cases of spondylolysis among 66 major injuries in competitive female gymnasts." More recently, a report by Dzilba and Gervin suggested that high level competitive gymnasts appear to have a disturbingly high incidence of problems including not only spondylolysis but also frank vertebral apophyseal compression fractures and mechanical back pain. ${ }^{2}$ They reviewed the case histories of five elite gymnasts with back pain and noted evidence of

radiographic de generative changes on all of their radiographs. Although the increased incidence of spondylolysis in grm. nasts has

received most attention, we have found that back pain in the gymnast may be due to a variety of causes, rang. ing from simple hvperlordotic back pain through vertebral body frac tures and disor- ders of the intervertebral discs.

Figure 1. A and B: A young gymnast is shown in a zero degree of lordosis, anterior-opening Boston brace for spondylolysis.

Figure 2. The hyperextension test, done with each leg, can be diag. nostic of spondylolysis if pain is elicited with the maneuver.

\section{SPONDYLOLYSIS}

Spondylolysis is certainly of of greatest concern as a cause of low back pain in the gymnast. These athletes will usually preesent with complaints plaints of low back pain, although this is sometimes associated with radiating pain into one or both buttocks. This pain is often first noted when the gymnast does a back flip or back walk-over and is often insidious in onset. OCcasionally, the gymnast will indict a single epi sode of hyperextension, or a fall, as initiating the pain

Although initially only elicited with gymnas ic maneuvers, the pain often be comes progressively more severe with activities of daily living, to the point where it may interfere with simply sittıng in school or sleeping. It is, however, usually relieved by supine positıoning.

Examination

Examination often re 
veals a child with a hyperlordotic posture. Forward bending is often painless, but rising to an upright position. particularly against resistance, may elicit pain. Even more specific, having the child stand on one leg then the other while hyperextending the back will often elicit pain. in the case of the unilateral pars fracture, pain while hyperextending the back and standing on the ipsilateral leg may prove to be diagnostic (Fig 2).

Neurologic examination of the lower extremities is usually unremarkable. although there is often some "relative" tightness of the hamstrings. It is important to emphasize the term "relative", since straight leg raising to 90 degrees from the supine position, while considered well with-

in the range of normal, may re

flect a loss of 30 or 40 degrees of motion in a pre viously hyper. flexible gym. nast. Careful questioning will usually reveal whether the athlete feels that he or she has lost flexibility, since flexibility of the back and hamstrings is a carefully monitored quality in the gymnast.

Plain radiographs of the lumbar spine, including anteroposterior. lateral, and both oblique views are obtaıned to assess the integrity of the posterior ele. ments Both oblique views must be obtained since only a single pars interar. ticularis mav be fractured.

Although

Grade I spondy-

lolisthesis may

be evident on

the lateral radiograph, particularly if a standing view is obtaining, it is ex. tremely rare to encounter a higher grade slip in these patients. If the plain radiographs are interpreted as being normal but a high index of suspicion for spondylolysis persists, based on the history and clinical findings rechnetium-99 radionuclear bone scan of the lumbar spine should be obtained (Fig 4). We have had several patients with initially "normal" plain radiographs who, on subsequent evaluation, showed clear-cut evidence of pars defects on additional radiographs. If this studv shows increased uptake of radionucleotide, we treat the child for a presumptive diagnosis of spondyloIvsis.

Unfortunately, not even a normal plain radiograph and a negative bone scan will absolutely rule out spondylolysis as a cause of low back pain. In addition the presence of an active bone scan should not be used as an absolute criterion for whether to institute treatment in a child with spondylolysis. We have had a number of cases of children

anterior-opening Boston brace for spondylolysis.

\section{Management}

The management of symptomatic spondylolysis in the young gymnast remains controversial. Some physicians are content to manage the patient symptomatically with limitation of activity, including no further gymnastics. Occasionally, a soft elastic garment, or corset, and flexion exercises are added to the regimen.

It is my opinion that this lesion should be treated as a fracture of the pars in terarticularis - albeit a stress fracture, the result of repetitive microtrauma and every attempt should be made to reduce the fracture and protect the spine in order to maximize the potential for healing. For this purpose we have used a rigid polypropy lene lum bosacral brace which is con structed with 0 degrees of lum. bar flexion, in an attempt to flat ten the low back and increase the chance for heal. ing by opposing the fractured pars elements (Fig. 1).

Once satisfacto$r y$ fitting of the brace is at tained, the child wears the brace 23 hours per day, with one hour out of the brace for bathing and exercises, which include abdominal strengthening. pelvic tilts, and antilordotic and lower extremity flexibility exer. cises. Brace treatment lasts for six months or until the bone scan, if initially

with low back pain, suggestive plain radiographs, and "normal" bone scans who have gone on to demonstrate further symptoms and, in one case, to progress to a first degree slip.

Figure 1. A and B, A young gymnast is shown in a zero degree of lordosis. positive, becomes negative

Most children become asymptomatic within three weeks after brace treatment is initiated, and we allow activities thereafter, including sports activities, so long as the child remains asymptomatic. For the gymnast, limıted bar work and tumbling are possible. but vaulting and most balance beam 
work are not possible

The results of brace treatment are promising. Our most recent review of the results of bracing in symptomatic spondylolysis demonstrated that 32 per cent of patients attained bony healing with this program and that 88 per cent of the 75 patients became pain free and were able to resume painfree sports activity even if bony healing could not be demonstrated by plain radiographs. ${ }^{8}$ it is important to em. phasize that athletically incurred spondylolysis is a stable lesion. We have not encountered a significant slip in any of our patients, despite continued activity. We therefore believe that the child and parents may be counseled that this lesion does not result in spinal instability but, rather, in potentially activity-limiting back pain in the young athlete or adult. As such, every effort should be made to heal the lesion. However, if a lesion does not heal but remains asymptomatic, we believe that the child may still safely participate in vigorous sports activities.

Although the presence of a positive bone scan at the site of fracture is indicative that the body is still trying to heal the lesion, and may reflect an enhanced potential for healing, the presence of a cold bone scan in a radiographic lesion should not be taken as a contraindicatıon to brace treatment. We have attained bony healing in five patients with initially cold bone scans Although we are pleased that 88 per cent of our spondylolysis patients treated with braces became asympto matic and resumed full sports activi ties, we are still experimenting with new brace designs and different treatment regimens. We are attempting to increase the healing rate above 32 per cent, since frank bony healing of the lesion must hold a better long-term prognosis.

\section{Vertebral body fracture}

Another cause of back pain in the young gymnast is fracture of the vertebral end plates, particularly at their anterior margins. These fractures $a p$ pear to be usually the result of repetitive microtrauma - most probably repeated flexion - which injures the anterior portions of the end plates and can result in frank vertebral wedging. In the gymnast, these fractures usually occur at the thoracoiumbar junction and may involve three or more vertebral bodies, although one or two levels of involvement are more common At times, these lesions may be labeled Scheurmann's disease, or "atypical Scheurmann's disease"“ Classic Scheurmann's disease, as characterized by Sorenson, occurs in the thoracic spine and involves at least three or more ver. tebral bodies, with greater than 10 per cent wedging of each body.10 True
Scheurmann's disease, of course, may also be the result, at least in part, of repeated fiexion microtrauma of the dorsal spine in a child who has tight lumbar lordosis, with forward flexion occurring in the dorsal spine rather
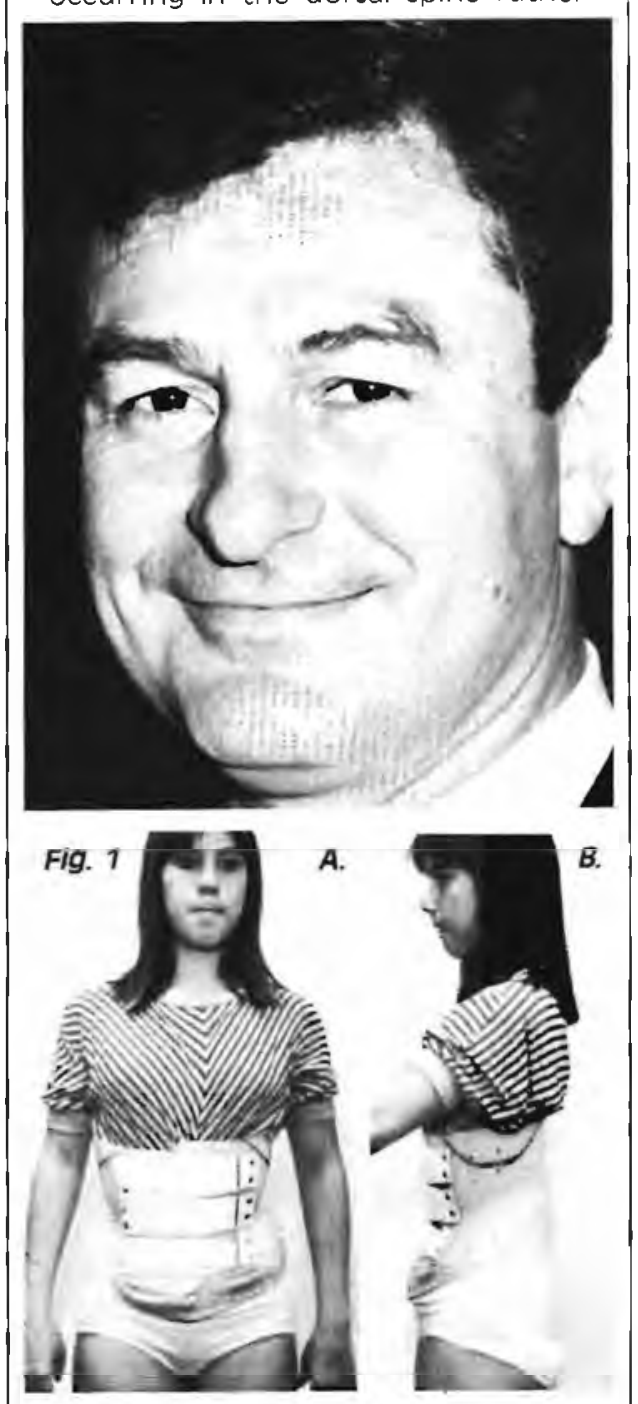

Fig. 2

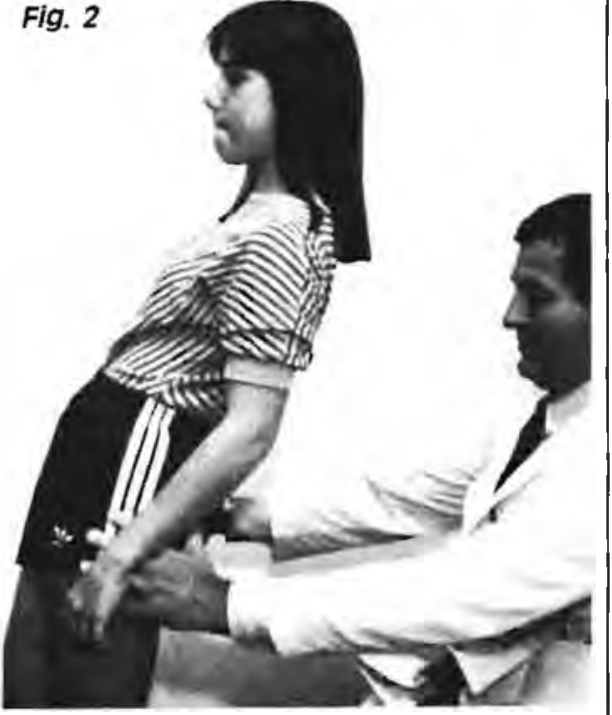

than in the lumbar spine below.

Once again, plain radiographs are usualIv sufficient to make the diagnosis of this microtraumatic fracture. A bone scan generally shows increased uptake at the lesions but is not necessary for diagnosis. Treatment is directed toward putting the spine at rest in order to facilitate normal bony healing. If significant vertebral body deformation has already occurred, additional steps should be taken to unload the front of the spine and maximize the potential for bony reconstitution. In our opınion, this is best accomplished with a semirigid thermoplastic brace. If the lesion is at the thoracolumbar junction, a brace with 15 degress of built-in lordo sis is used to immobilize the back and unload the front of the spine. Brace treatment is used, once again, for 23 hours per day and is contınued until bony healıng and vertebral body reconstitution are evident - usually four to six months.

These children usually become asymp. tomatic in three or four weeks, and again, limited gymnastic training is allowed as long as they remain asymptomatic As with spondylolysis, a high index of suspicion when the athlete first complains of back pain and early inıtiation of treatment will maxımıze results.

\section{Discogenic back pain}

The differential diagnosıs of back pain in the young gymnast must include dis cogenic back pain. This disease in the prepubescent child is rare, but its incidence in the adolescent, particularly in the athletically active adolescent, appears to be increasing.

The presentation of this disease in the young athlete may be quite different than that usually encountered in the aduit. Back pain, as such, may be a relatively minor complaint. More frequent Iy, the child, or his or her coach, may notice a loss of hamstring flexibility sometimes unilateral, or the onset of a sciatic scoliosis

Dragnosis may be difficult to make. Physical examination may reveal evi dence of sciatic irritation, with positive straight leg raising or a positive La segues sign. Loss of reflexes or frank muscle weakness is unusual. Often however, there will be a loss of the ability to forward flex the spine or reverse the lumbar spine on forward flexion and this movement may elicit pain. As with all disc disease, conservative treatment aimed at resting the back In a neutral position and avoiding further pain or muscle spasm is the primary mode of treatment. In our ex perience, the adolescent with disc disease will usually respond rapidly to bed rest with decreased pain and muscle spasm, but this response may not last If activities are resumed too early. We will generally advise the family that their child will be out of vigorous sports activities for 6 to 12 months following a frank episode of discogenic

CONTINUED ON PG 15. 

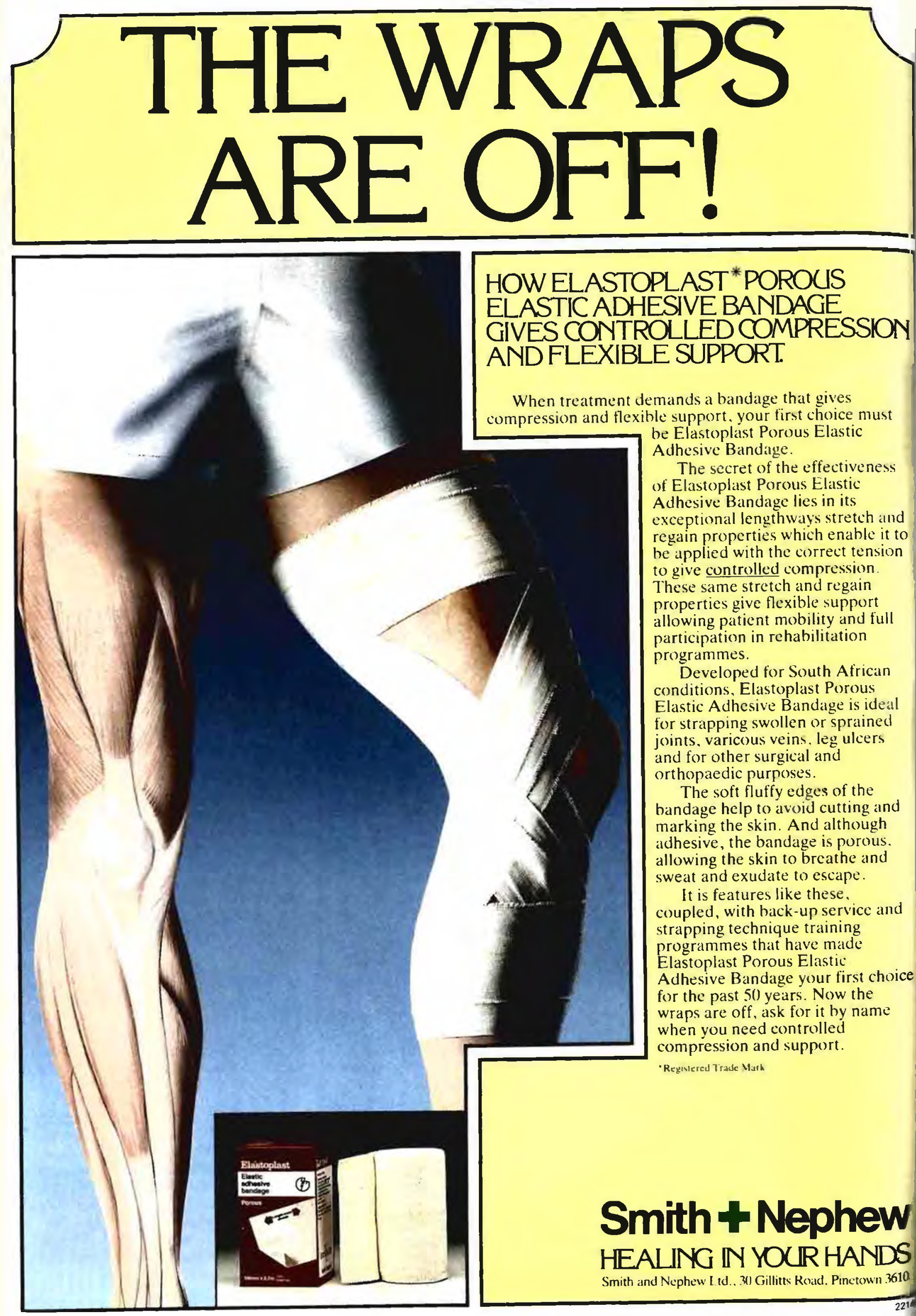


\section{ULTRA MAN}

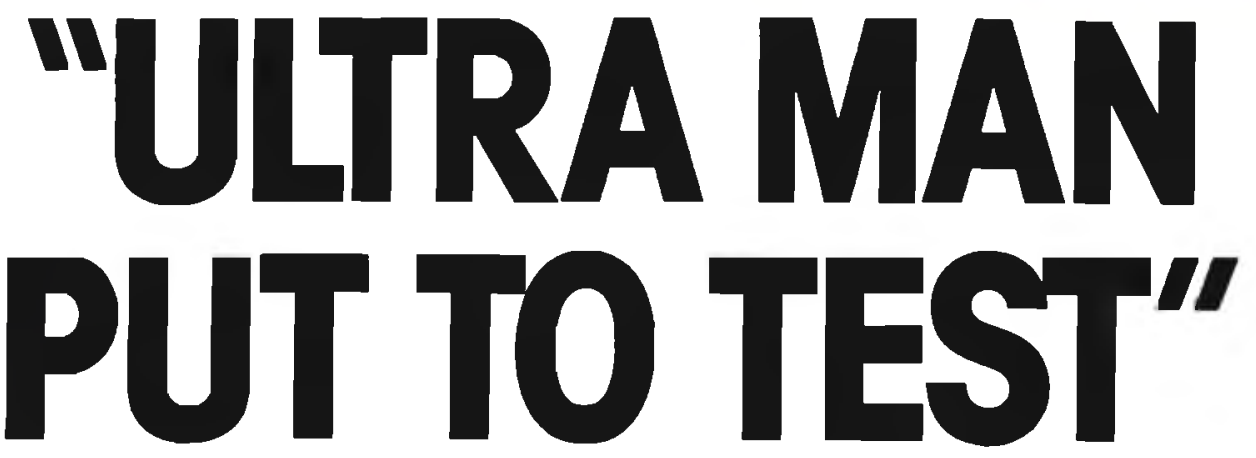

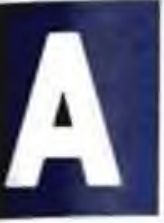

multi-disciplinary endurance event such as the elements which go to make up the Ciba-Ceigy sponsored Ultra Man, makes special demands, even on the ultra fit athlete

The Institute of Sport Research and Training at the University of Pretoria is paying special attention to the physiodynamics of the various events involved. Problems could, for instance arise in an athlete who has successfully completed the Comrades Marathon on many occasions, when he is challenged to turn his hand, or rather his muscles, to a different ultra distance discipline such as cycling or canoeing.

Under the guidance of Hans Daehne, the Sports institute puts athletes through their paces, quite literally, under controlled laboratory conditions. Leading athletes such as Iron Man Ed die King, and Transvaal flyhalf Schalk Naude, subjected themselves to the In stitute's battery of tests. These include anthropometric tests, i.e body type measurements such as mass/ height, fat weight ratios and muscle measurements.

By specialising in one ultra distance dis. cipline, muscles are selectively deve loped and strengthened. Eddie King with his dominant emphasis on run. ning and cycling was unable to reach his ankles due to shortening of the hamstrings, whereas schalk Naude could place his hands flat on the floor The Cybex Test measures muscle strength and endurance. Under strict conditions of measurement, both the extension and flexion of a limb joint is measured through its total range of motion. While the athlete delivers his maximum output, the Cybex computer plots the appropriate curve. If any muscle system is damaged, the injury will show up as a deviation on the $\mathrm{Cy}$. bex tracing. In this way the precise location and severity of injuries can be demonstrated and appropriate physio therapy or corrective exercise routines prescribed.

The Institute emphasises the impor- tance of style in any sport. but particularly in running. Top notch cyclists and canoeists tend to have an awkward running style, and it is in the running events that the most injuries during the Ultra Man sequence are expected. The institute can however get canoeists of on the right foot. so to speak. Leaflets are available on running style - the importance of stance, followthrough with the ball of the foot and good arm movement. During the demo period even Eddie King by makıng a minor adjustment to style was able to smooth his performance.

A computerised spirometer is used to measure lung func. tion and lung capacity. Wired up like an astronaut, the athlete performs against set standards while instruments measure his capacity to transport oxygen through heart and lungs and convert it into energy at muscle level. This complex parameter, the VO2 max, a measure of the body's ability to accept and utilise oxygen is also an index of performance on the athlete's path to superfitness

\section{SCHALKNAUDE
DEMONSTRATING THE} SPIROMETER TEST

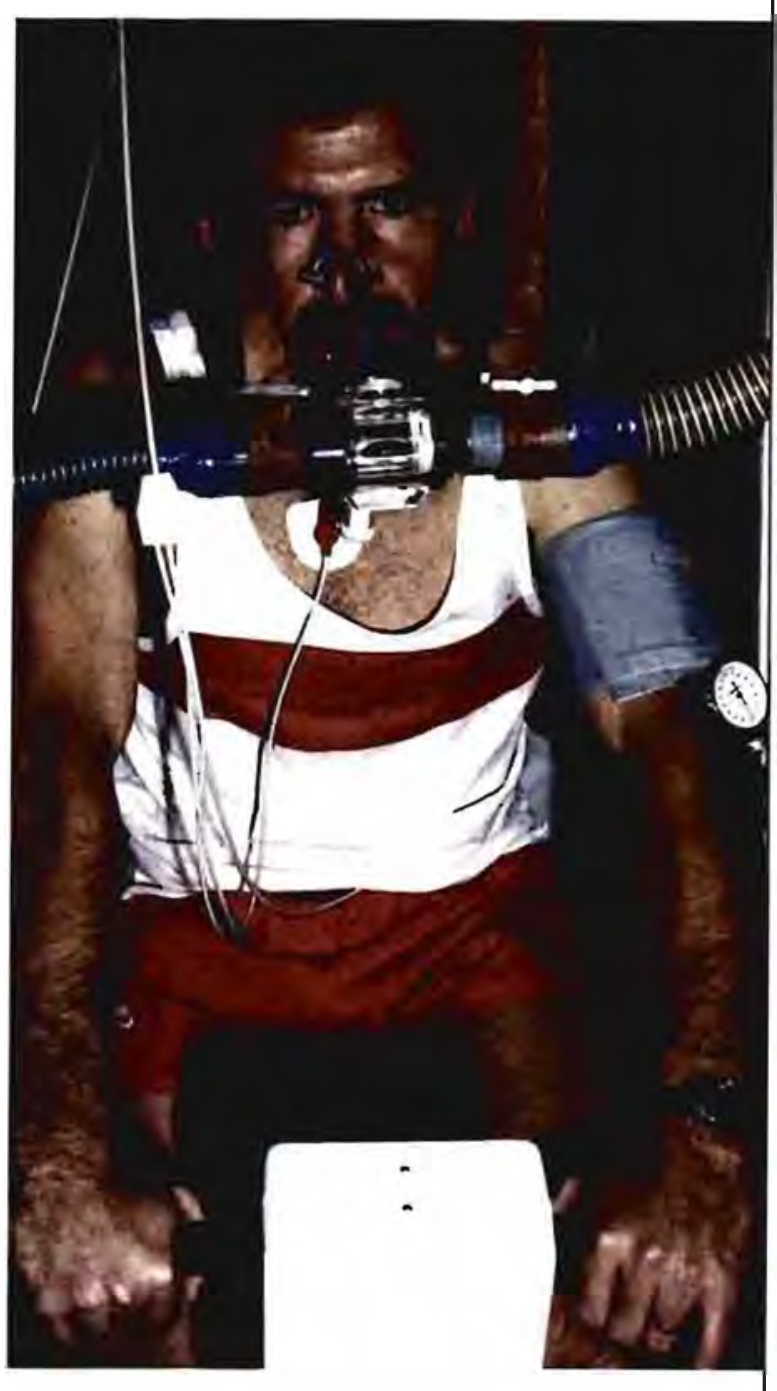

(B)

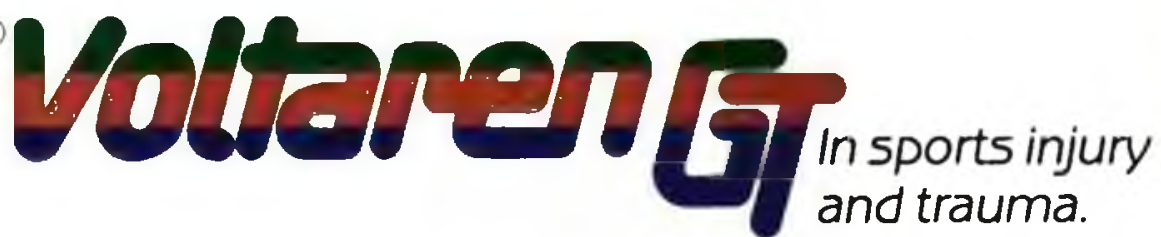

diclophenac sodium50mg (enteric coated tablets) reg mo k/3.1/253 (Wet/act 101/1965) [53 


\section{U}

Itraman will test the best

with entries having closed for the Johannesburg Stock Exchange Marathon, the first op tional event within the Ultra Man competition, I think it appropriate to reflect developments withın Uitra Man to date

Response to the competition has been nothing short of phenomenal if one considers the rather substantial chal lenge that entrants are faced with. At the time of going to press 132 en trance applications had been received and if the encouragingly numerous queries that are received on a daily ba sis are anything to go by, a similar number of entries yet again can be anticipated.

There are an abundance of top competitors who have taken up the challenge including the likes of $\mathrm{Dr}$ "Tiffy" King, Graeme Pope-Ellis and Ceorge Janos, with unconfirmed rumours having it that Danny Bigg's entry is in the pipeline. It seems unlikely that as a former gold medalist in the Iron Man, Hansa Duzi and Comrades, Danny will turn down the opportunity to earn a potential R18000 from a competition that seems tailor made for him. Whatever his decision, the nature of the Ultra Man is such that it would be most difficult to speculate who the winner might be. The tactical element that competitors are faced with in terms of choosing events is bound to add a decisively interesting dimension to the challenge, with a better than average competitor who completes all eight events standing a good chance of being up there with the best of them.

A misconception that has developed amongst interested parties is that UItra Man will have their final points standing calculated on an average rather than on an aggregate basis. The opposite is in fact the case which means that any event completed will yield a

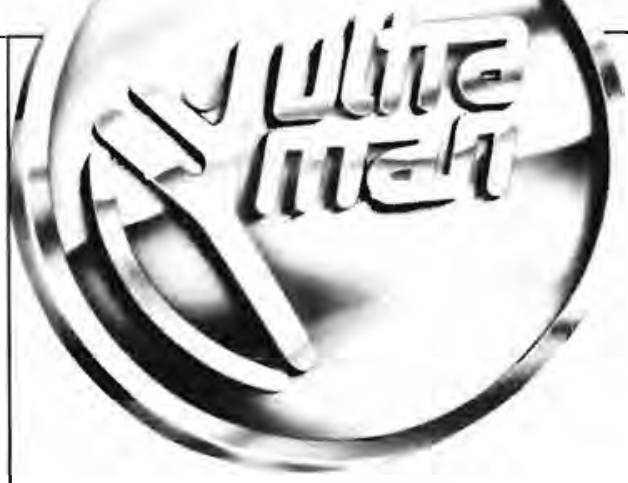

positive addition of points to a compe titors total. A maximum of 100 points will be earned by the first Ultra Man home in each event which means that a total of 800 points could be earned in the unlikely event of one athlete winning all eight races.

For those people who have not yet en tered, I would like to stress that entries will be welcomed up to November 15 The first compulsory event is the Vas. byt Ultra Man Cycle Challenge on November 28 , a $165 \mathrm{~km}$ cycling event which is dominated by a series of rather daunting hills. Entrants for Ultra Man will be mailed information on this event which will include a map of the route.

With the "Vasbyt" looming I would like to take this opportunity to wish our competitors the best of luck in this event, the second out of the eight en durance tests that lie ahead.

\section{Bester takes Ultra Man Lead} comrades marathon specialist Nick Bester takes 100 ultra Man bonus points into the $165 \mathrm{~km}$ Vasbyt cycle ultra mara thon on November 28 after finishing ninth in the recent $50 \mathrm{~km}$ Johannesburg Stock Exchange marathon.

The JSE was the first optional event on a gruelling Ultra Man fixture list and Bester who was 25th in the Comrades mara thon this vear in 6:12:08, finished ninthaf ter the run from Johannesburg to voortrekkerhoogte with a time of 2:59.07 As the top Ultra Man finisher, Bester

Fromleft toright:CraemePope-Ellis, Danny Biggs, Dr Eddie King, NiC Bester, PietMare. earned an automatic 100 bonus po ints. Points were awarded to the other Ultra Man contenders according to a special formula and Piet Mare grabbed second place on the log with 92,38 points after clocking 3:12:54 in the JSE.

Third is top endurance athlete Danny Biggs, who ishaving a "fullgo" atUltra Man after a disappointing Comrades marathon this yearin which hefinished out of the gold medals in 18th place

Biggs picked up 85,99 points for his 3:24:28 in the JSE, just ahead of Duzi "kıng" Graeme Pope-Ellis. "The Pope" clocked 3:25:51 for 85.22 bonus points, while Pierre de Jager is fifth on the UItra Man log with 84,72 points from a time of 3:26:45

Phillip van Tonder is sixth $(84,02$ points: JSE time of 3:28:01), followed by Roger Zipp $(83,13 ; 3: 29: 38)$; Phillip Demosthenous $(82,72 ; 3: 30: 22)$, veteran Ceoff Mat. thews $(81,77 ; 3: 32: 06)$ and Kenneth Poole $(81,71 ; 3: 32: 12)$.

Leading the woman in the series sponsored by Ciba-Geigy is experienced ultradistance athlete Priscilla Carlisle, who earned 68,76 pointsfrom her JSE timeof 3:55:37

SallyLuckoff has 59,37 from 4:12:44 and Sandra Niemand 45.45 from 4:37:47

A total of 164 Ultra Man competitors ran the JSE in search of bonuspoints. Among them was two-time Leppın Iron Man triathlon champion Eddie King - 17th on the log with 80,02 points from time of 3:35:15

The total number of Ultra Man entrants so far is 275 , and entrieswill be accepted until October 30

Missing from the JSE was current Sunday Times/Leppin Iron Man champion Henk watermeyer

He will, however, be one of the top contenders in the vasbytultramarathonand he still has the opportunity to boost his points tally in the Midmar mile swim in February, Argus cycle tour in March and Two Oceans marathon in April

Organised by SpekeCycling Club, the Vasbyt ride starts (6am) and finishes at the

CONTINUED ON PAGE 19

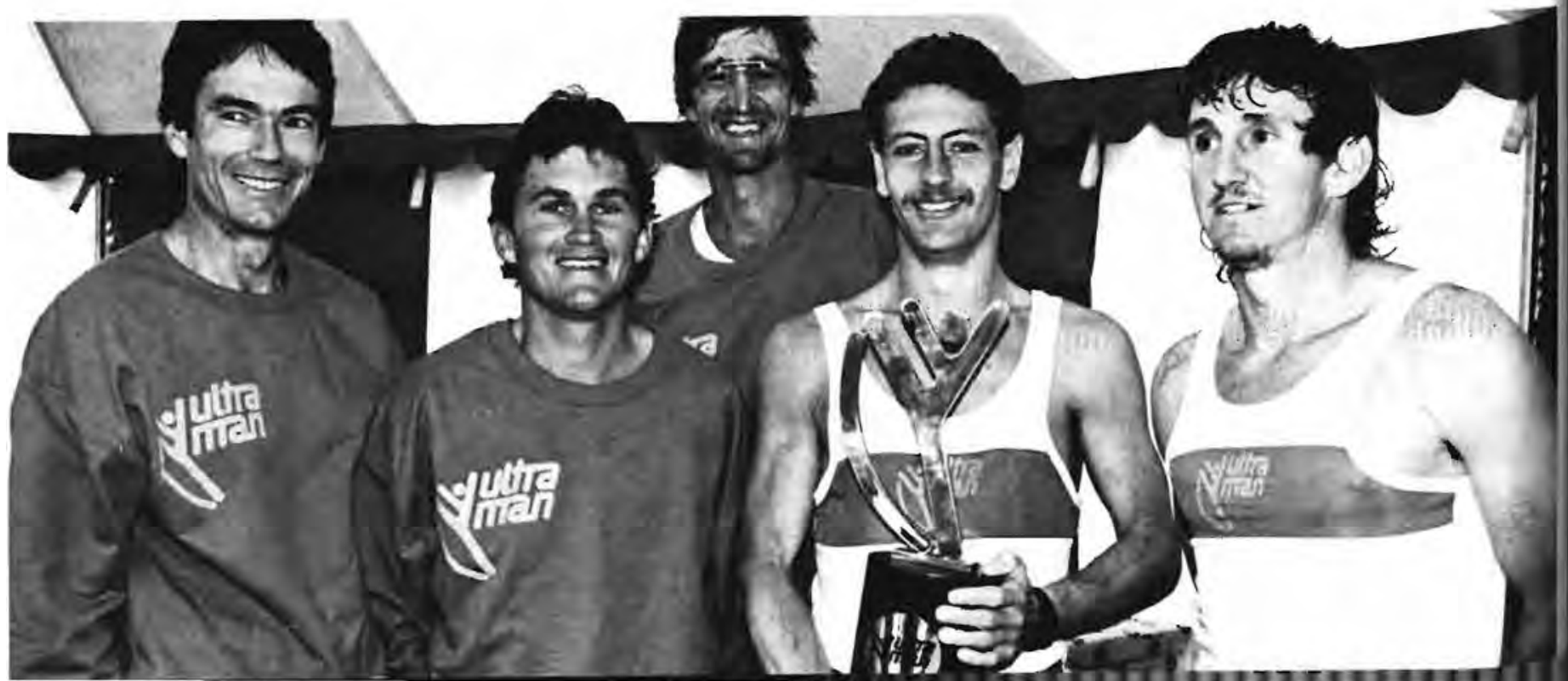




\section{FEATURE}
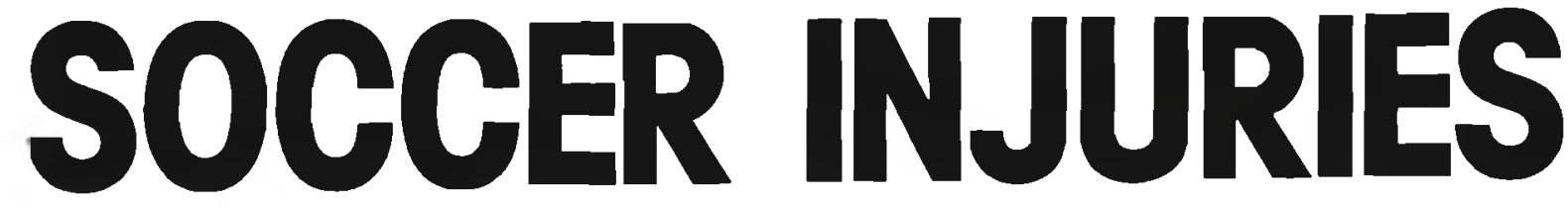

\section{Survé 4th Year Medical Student, J. Ranchod 4th Year Medical Student, \\ A.N. Kettles Registrar From: The Department of Community Health, \\ University of Cape Town.}

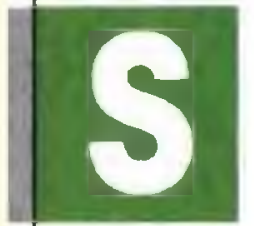

\section{ummary}

Soccer is the most wide. ly played sport in South Africa yet no study of soccer injuries in this country has apparently been published

This survey examines the relationship of injuries to factors, both intrinsic and extrinsic to the player All injuries are classified according to type, site, seve rity, recurrence, and manner of sustain ing the injury. A relationship between injury and some of these factors is shown, the most important being field condition, protective equipment and division plaved in. Suggestions are made as to how to reduce these injuries. It is also recommended that a follow up study be done on some of the relationships emerging from this study.

\section{Introduction}

Soccer is the most widely played sport in the world. ${ }^{1}$ More than 40 million active plavers were registered with the Federation of International Football Association in 1982. ${ }^{2}$ As in other contact sports, soccer has an inherent injury risk ${ }^{3.4}$ and soccer is considered to be responsible for $50.60 \%$ of all sports injuries in Europe.

Epidemiological studies have been performed on soccer injuries ${ }^{1}$ but it appears that no such information is yet available on South African soccer, despite the fact that soccer surpassed rugby as the most popular sport in this country in $1984 .{ }^{\circ}$ As an initial step towards the prevention of soccer inju ries in South Africa, the principal authors determined the distribution and pattern of soccer injuries among amateur soccer players, over a period of 9 weeks, extending midway into the 1985 playing season

\section{Materials and Methods}

For the purposes of this survey, an injury was defined as one that required the attention of the first-aid staff available at each match.

The following procedure was adopted to identify injuries occurring in matches included in the survey: on the morning of each match - Saturday, the first aid teams allocated to each match were given a detailed explanation of the project and the questionnaire, which also had an explanatory sheet attached. Specific instructions were given to ensure that a questionnaire was completed for each player who received first aid attention during the match. The two allocated first aid. ers were accompanied by an occupational therapist or the authors until

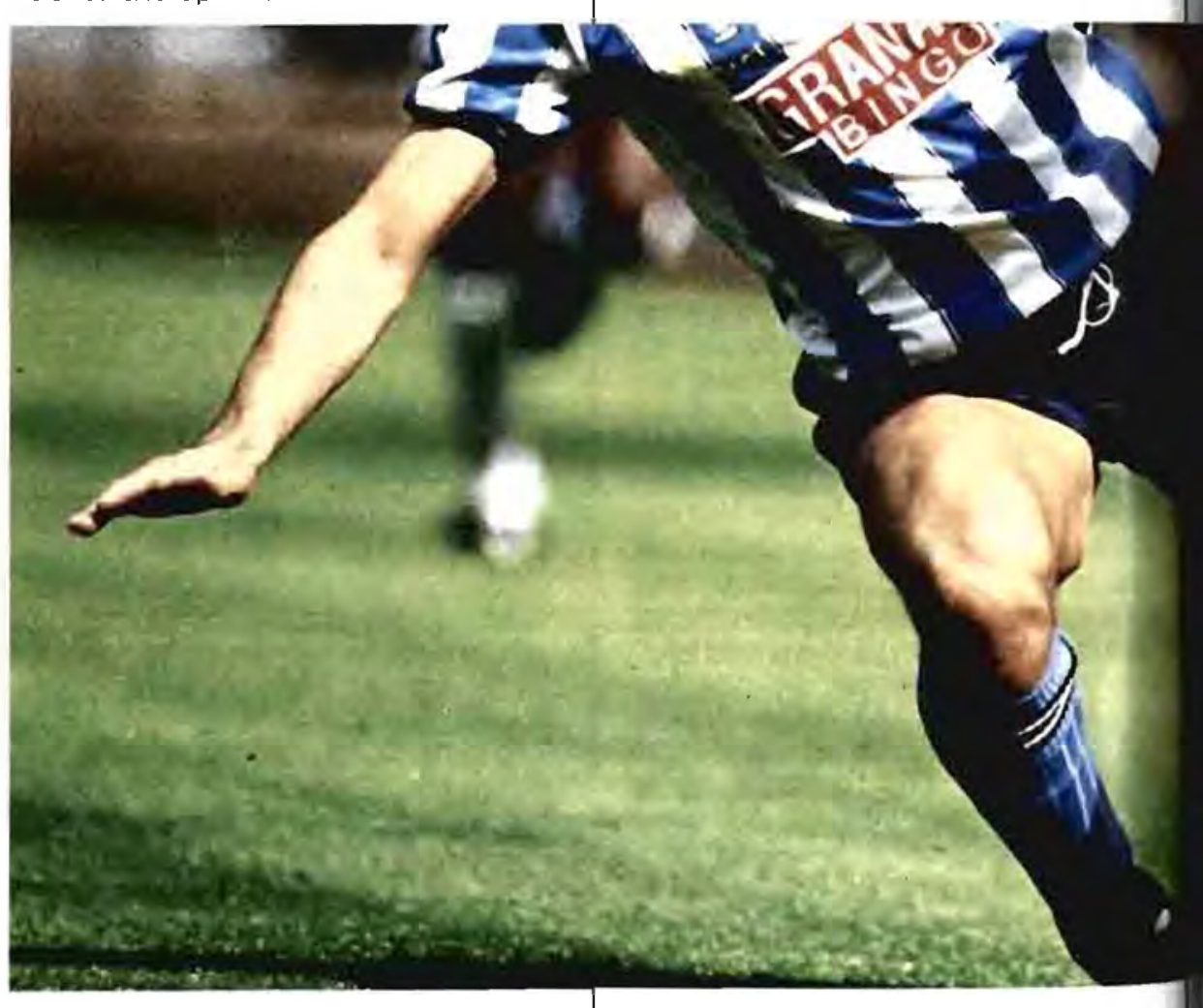

such time as they were competent to complete the questionnaire on their own. They were then checked at regu lar intervals to ensure that a high standard was maintained. The questionnaires were collected after each match The questionnaire included data about factors both intrinsic and extrinsic to the players, e.g. age division, playing position, field, weather condition, injury (type), protective equipment worn by players, referee, etc.

Each field was graded according to the following criteria: surface, evenness, presence of tufts and holes, clarity of markings.

The survey population consisted of senior members of the Cape District Football Association - an amateur football body with 22 clubs and a total membership of \pm 1000 players. Senior players were defined as all players in the under 18, under 21, 2nd, 1st and Premier Divisions.

To assess the opinion of players about factors potentially leading to soccer injuries, a random sample of 100 players was chosen, using random number tables Each player was asked to complete a questionnaire listing eight possible factors from which they were asked to indicate the three which they considered were the most important. 


\section{Results \\ Number and Incidence Rate of injurles \\ A total of 227 games were played by 64 teams of 11 players each while game duration varied with division. The total number of playing hours studied was 5826 . A total of 73 injuries were recorded, giving an overall injury inci- dence of 1 injury per 80 playing hours, or 12,5 per 1000 hours played. This reflects an average risk of 1 in 68 per game for each plaver.}

\section{Table I: Injury distrlbution over divislons and time.}

\begin{tabular}{|c|c|c|c|c|c|c|}
\hline Division & $\begin{array}{l}\text { No of } \\
\text { teams }\end{array}$ & $\begin{array}{l}\text { No. of } \\
\text { games }\end{array}$ & $\begin{array}{l}\text { No. of } \\
\text { injuries }\end{array}$ & $\begin{array}{c}\text { No. of } \\
\text { injuries } \\
\text { per game }\end{array}$ & $\begin{array}{c}\text { Total } \\
\text { man } \\
\text { hours } \\
\text { plaved }\end{array}$ & $\begin{array}{c}\text { Incidence } \\
\text { rate per } \\
1000 \text { man } \\
\text { hours } \\
\text { played }\end{array}$ \\
\hline $\begin{array}{l}\text { U18 } \\
\text { U21 } \\
\text { 2nd } \\
\text { 1st } \\
\text { Premier }\end{array}$ & $\begin{array}{r}14 \\
10 \\
22 \\
9 \\
9 \\
\end{array}$ & $\begin{array}{l}38 \\
40 \\
95 \\
24 \\
30 \\
\end{array}$ & $\begin{array}{r}14 \\
19 \\
5 \\
11 \\
24 \\
\end{array}$ & $\begin{array}{l}0,37 \\
0,48 \\
0,05 \\
0,46 \\
0,80 \\
\end{array}$ & $\begin{array}{r}836 \\
880 \\
2438 \\
792 \\
880 \\
\end{array}$ & $\begin{array}{r}16.67 \\
21,74 \\
2,23 \\
13,89 \\
27.0\end{array}$ \\
\hline TOTAL & 64 & 227 & 73 & 0,32 & 5826 & 12,53 \\
\hline
\end{tabular}

The overall number of injuries during each week of the season was not greatIy different and varied from 6 to 10 per showed the highest injury incidence per game played ie 0,8 , while the aver age for all divisions was 0,32 injuries per game.

\section{Injury by Playlng Position}

Table II shows the relationship between plaving position and number of injuries The majority of injuries occurred to midfield players $(32 \%)$ and the least to goalkeepers $(15 \%)$. However, there is only one goalkeeper per team, and on average three backs, three forward and

different injuries with regard to division or playing position, although lacerations were relatively more common in defence positions and sprains more in attacking positions

Table II: Injury Incidence In different playing positions

\begin{tabular}{|c|c|c|}
\hline Position & $\begin{array}{c}\text { Number } \\
\text { of } \\
\text { Injuries }\end{array}$ & $\begin{array}{l}\text { Corrected } \\
\text { Percentage } \\
\text { of Injuries }\end{array}$ \\
\hline \multirow{5}{*}{$\begin{array}{l}\text { Goalkeeper } \\
\text { Back } \\
\text { Midfield } \\
\text { Forward }\end{array}$} & $11(15 \%)$ & $37,0 \%$ \\
\hline & $19(26 \%)$ & $21,3 \%$ \\
\hline & $23(32 \%)$ & $19,3 \%$ \\
\hline & $20(27 \%)$ & $22,4 \%$ \\
\hline & $73(100 \%)$ & $100 \%$ \\
\hline
\end{tabular}

Table III: Distribution of type of Injury

\begin{tabular}{lc} 
Type of Injury & Number of Injuries \\
Sprains & $31(42 \%)$ \\
Lacerations & $23(32 \%)$ \\
Strains & $13(18 \%)$ \\
Contusions & $5(7 \%)$ \\
Fracture & $1(1 \%)$ \\
\cline { 2 - 2 } & $73(100 \%)$ \\
\hline
\end{tabular}

Site of Injury are corrected accordingly, the incdence of injury is greatest for the

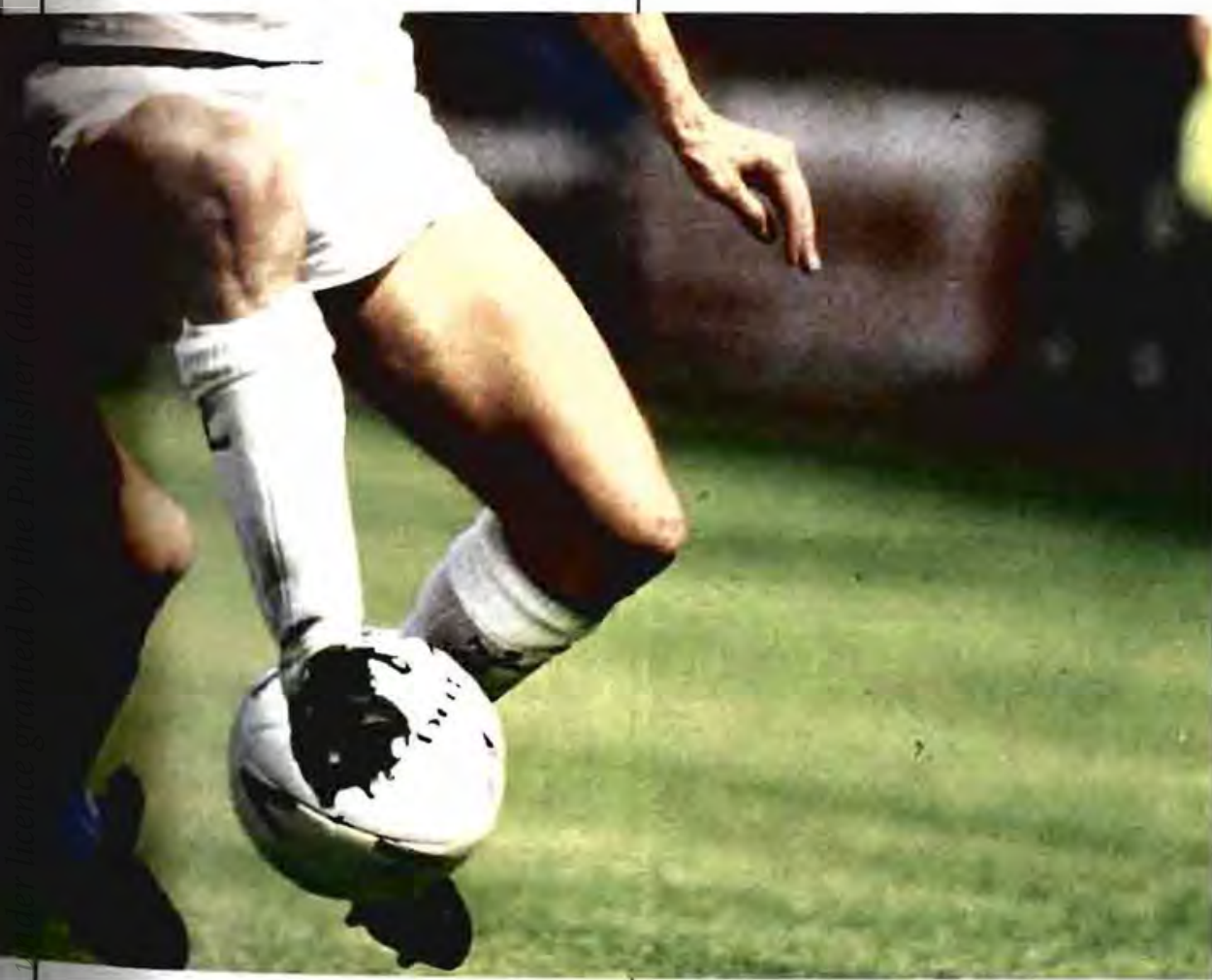

week, of which $90 \%$ were new injuries and $10 \%$ recurrences

The proportion of injuries as distributed over the divisions showed that they occurred most in the premier league $(33 \%)$. followed by the "Under 21 " $(26 \%)$ and Under 18 " category $(19 \%)$. The number of playing hours "at risk" for these three divisions were approxi mately equal, although the number of games differed. The premier division

\section{goalkeepers}

\section{Types of Injury}

Table III shows the frequency of each type of injury. While there was only one fracture, $75 \%$ of the injuries comprise sprains $(42,5 \%)$ and lacerations $(31,5 \%)$, while $58 \%$ of sprains occurred to the ankle, $19 \%$ to the knee and $13 \%$ to the hand. There was no significant difference in the relative proportion of

\section{Table IV: DIstrlbution of Injurles over anatomlcal sites}

\begin{tabular}{|c|c|}
\hline Site & $\begin{array}{l}\text { Number o } \\
\text { Injuries }\end{array}$ \\
\hline Ankle & $18(25 \%)$ \\
\hline Thigh & $12(16 \%)$ \\
\hline Shin & $9(12 \%)$ \\
\hline Hand & $8(11 \%)$ \\
\hline Knee & $5 \quad(7 \%)$ \\
\hline Groin & $4 \quad(6 \%)$ \\
\hline Back & $4 \quad(6 \%)$ \\
\hline Foot & $3 \quad(4 \%)$ \\
\hline Calves & $3(4 \%)$ \\
\hline Elbow & $2 \quad(3 \%)$ \\
\hline Face & $2(3 \%)$ \\
\hline Neck & $1 \quad(1 \%)$ \\
\hline Shoulder & $1 \quad(1 \%)$ \\
\hline \multirow[t]{2}{*}{ Ribs } & $1 \quad(1 \%)$ \\
\hline & $73(100 \%)$ \\
\hline
\end{tabular}

Lower limb injuries accounted for $74 \%$ of all the injuries (54 out of 73), of which the ankle accounted for a total of $18(25 \%)$. The upper limb injuries comprised $15 \%$ of the total (11 out of 73), with the hand accounting for 8 of these

\section{Severity of Injury}

About one in three of the injured players had to leave the field whilst the remainder were able to play on. In the total of 227 games played, 23 injuries could be considered severe, defined as when a player was forced to leave the field as a result of injury.

This gives an incidence rate of 1 severe injury per 10 games played, or a severe injury incidence of 4 per 1000 player hours. 


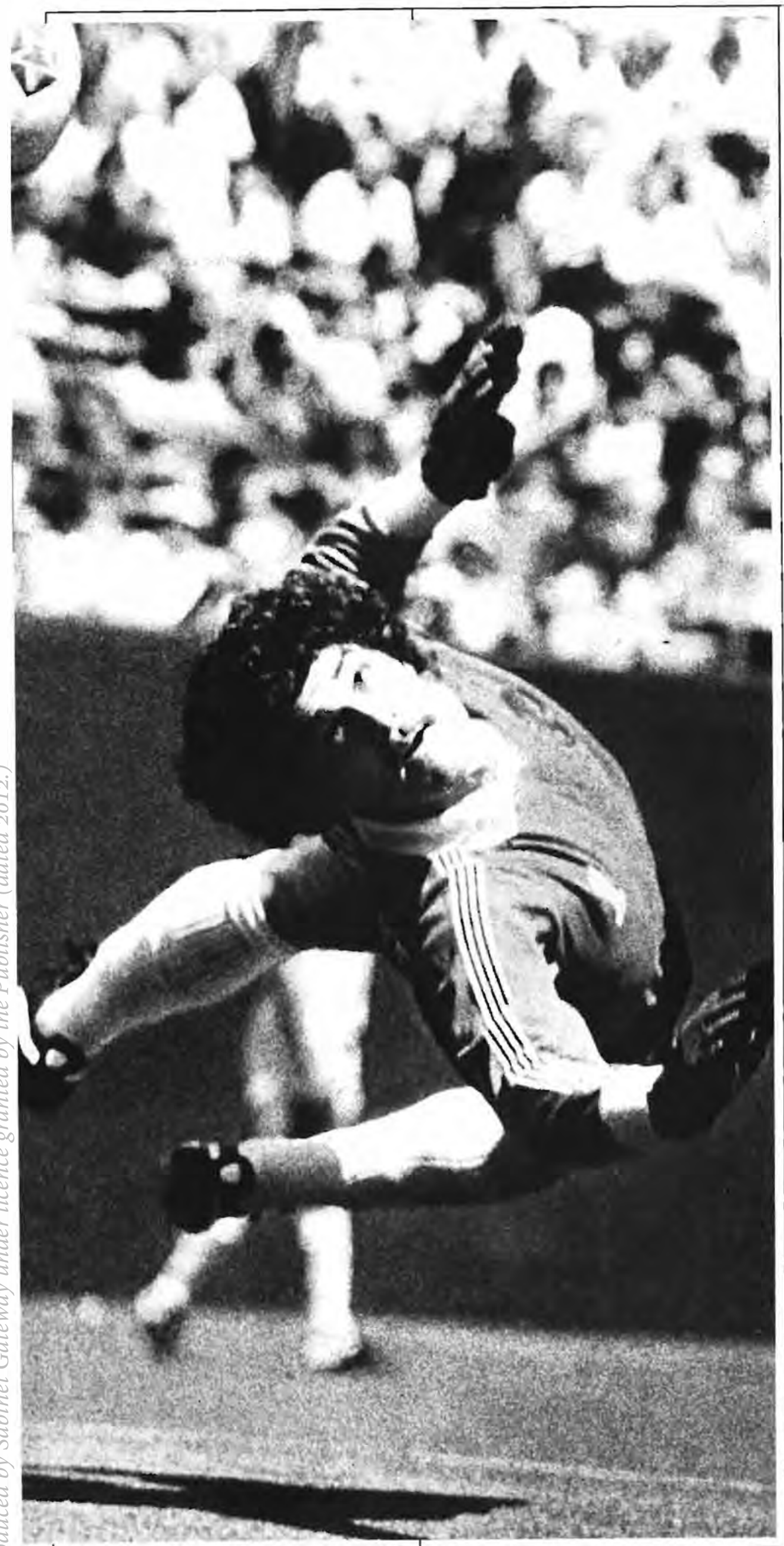

Field Conditions

All fields on which matches were played were graded according to a checklist with a maximum score of 40 . The num. ber of injuries and of playing hours for each field was determined, and the injury incidence per 1000 hours was cal. culated

When and how injuries occurred Most injuries occurred in the second half $(47$, or $64 \%)$. The commonest method of injury was a foul (42, or $57 \%$ ) of which 30 occurred in the second half. When one combines fouls and fair tackles (53) the majority (40, or $76 \%$ ) occurred in the second half

\section{"The high number of sprains In the forward and midfield positions could be due to the skilful dribbling involved in these positions, especially since 16 of the 22 sprains recorded were ankle sprains.}

Influence of individual preparation It was established that $39 \%$ of injured players had warmed up before games and practices, and $90 \%$ had attended at least two soccer practices per week. In general $90 \%$ of injured players considered themselves fit or very fit. The injured players were virtually equally divided over those wearing screw-in studs (37 or 51\%) or multi-studs (36 or $49 \%$ ) and no relationship could be found between the type of studs worn and the injuries sustained. Shin guards were worn by $47 \%$ of players and none of these players suffered shin lacerations. Of the injured players, $47(64 \%)$ participated competitively in another sport. 


\section{continued from page 6}

back pain with sciatica

As with spondylolysis and vertebral apophyseal fractures, we have found brace treatment useful in managing these adolescent athletes with disc disease We present this treatment program to the patient and parents as a way of resting the back while allowing the patient to continue being ambulatory and active, as well as continuing in school. With the patient who has disc disease, the brace that has been best tolerated, particularly early in the treatment regimen, has been the somewhat softer and more flexible polyethylene brace with 15 degrees of lordosis built into the brace.

As might be expected, the success rate for disc disease with the brace and rest program has not been as high as that for spondylolysis or vertebral end plate fractures. In our initial series, only approximately 50 per cent of the young athletes with discogenic low back pain were able to return to full sports activities without pain.

It would appear wise, if at all possible, to avoid discectomy in the adolescent with disc disease. Although the natur al history of adolescents after discec tomy has not been well studied, the re cent review by De Orio and Bianco sug gested that there was a relatively high incidence of continuing back com plaints in these patients as adults.'

The recent increased interest in chymopapain injections for discogenic low back pain with sciatica may have a particularly useful application in the adolescent or young adult with disco. genic back pain. In such patients, of course, the disc rupture appears to be the primary event and is usually not associated with degenerative changes in the facet joints or posterior elements. Thus, chymopapain injection to mechanically decompress the bulging disc and the associated nerve irritation might well allow adaptive changes to occur in the associated elements of the spine. The long-term result may be a significantly lower incidence of subsequent degenerative changes and back pain in this population.

of course, the child with progressive neurologic symptoms, bladder and bowel complaints, or serious motor loss is a candidate for surgical decompres sion, as in the adult.

\section{Spondylogenic back pain}

When the gymnast with back pain has been carefully evaluated and the aforementioned diagnoses of spondylolysis, apophyseal fracture, or disc disease have been ruled out, the presumptive diagnosis of spondylogenic back pain may be made. This is usually associated with a hyperlordotic posturing of the lumbar spine, tight hip flexors, and frequently, relatively tight hamstrings

\section{and lumbodorsal fascia.}

Children with spondylogenic back pain in association with sports activities wili usually respond to a well supervised exercise program of abdominal strenghtening, lumbodorsal and hamstring stretching, and antilordotic posturing of the lumbar spine. The pelvic tilt performed in both the supine and standing position is the foundation of this exercise program. Surprisingly, a survey of gymnasts in the Boston area by Dr Michael Goldberg revealed that a number of these were relatively lacking in abdomınal strength."

In some cases, exercises alone have not been sufficient to reverse the lordotic posturing of the low back and relieve the back pain. In such cases, a O-degree, anterior opening plastic brace has proved to be very useful to relieve the child's pain and allow restoration of function.' These children usually became asymptomatic in three to four weeks. Bracing is usually continued for three to four months in combination with the exercise program outlıned earlier, then the use of the brace is tapered.

\section{"Young gymnasts complaining of back pain must never be passed off as having sustalneda back strain or "muscle spasms" and treated symptomatically."}

\section{Tumor and infection}

A final, extremely important consider. ation must always be remembered in the young gymnast complaining of low back pain, even pain that is apparently associated with traumatic athletic activities. Tumors of the axial skeleton and infectious processes of the disc or end plates must always be considered in the differential diagnosis of the young athlete with low back pain. The incidence of osteogenic sarcoma of the axial skeleton is low in any age group, of course, but the adolescent and young adult are particularly susceptible to this disease process. In addition discitis, although more common in the somewhat younger child or young adolescent, can also be encountered in the older adolescent involved in sports activities A recent case of ours outlines this point very clearly. This was the case of a 17-year-old elite tennis player who began complaining of back pain and radiation of pain into the buttocks. This pain was severe enough to warrant hospital admission and evaluation. A presumptive diagnosis of discogenic back pain with severe sciatica was then obtaıned. However, further evaluation showed elevation of the sedimentation rate and a positive bone scan at the L1-L2 level. Subsequent radiographs confirmed progressive narrowing of the L1-L2 level, and the diagnosis of disC space infection was made. The patient responded well to a program of rest. brace immobilization, and antibiotic treatment and did not require decompression of the disc.

\section{Summary}

The complaint of low back pain in the adolescent must never be taken lightIy. A high index of suspicion should be particularly entertained in a child par. ticipatıng in gymnastic training or competition. As noted in this article, steps can now be taken, particularly if a specific diagnosis is made early, to institute specific treatment with a high likelihood of success. Young gymnasts complaining of back pain must never be passed off as having sustained a back strain or "muscle spasms" and treated symptomatically. Persistent back pain bevond two weeks warrants, in our opinion, a complete evaluation, careful history and physical examination, a four-view radiographic assess. ment of the spine, and, if necessary, bone scans or other more advanced techniques to make a specific diagnoSIs of the cause of the pain.

\section{References}

1. De Orio J $K$ and Blanco AJ: Lumbar disc exc sion in children and adolescents. I Bone Joint Surg. 64A:991.995, 1982

2. Dzilba, R.B, and Cervin, A.l: Irreversible soinal deformity in Olympic gymnasts. Annual Meeting. American Orthopaedic Society for Sports Medicine Anaheım, California, March 1983

3. Coldberg. M.A. Gymnastic inuries. Orthop Clin North Am 11:717.724, 1980

4. Hensinger RN Back pain and vertebral changes simulating Scheurmann's disease Orthop Trans. 6:1, 1982.

5 Jackson, DW, Wiltse, LL, and Cirincione, R.L: Spon dylolysis in the female gumnast. Clin. Orthop. 117:68-73, 1976

6. Micheli. L.J: Low back pain in the adolescent Differential diagnosis. AM. J. Sports Med 7:362-364, 1979

7. Michelı. L.J. Hall, J.F., and Miller, M.E.. Use of the modified Boston brace for back injunes in athletes Am. J Sports Med., 8:351-356, 1980.

8 Michell $L$ J and Steiner E M. The use of a mod fied Boston brace to treat symptomatic spondylol. vsis Orthop. Trans. 7:20, 1983.

9 . Snook GA. Inuries in women's gymnastics. AM S Sports Med. 7:242-244, 1979

10. Sorenson, H.K. Scheurmann's Juvenile Kyphosis Copenhagen, Munksgaard, 1974.

Division of Sports Medicine

Children's Hospital Medical Centre

300 Longwood Avenue

Boston. Massachusetts 02115 


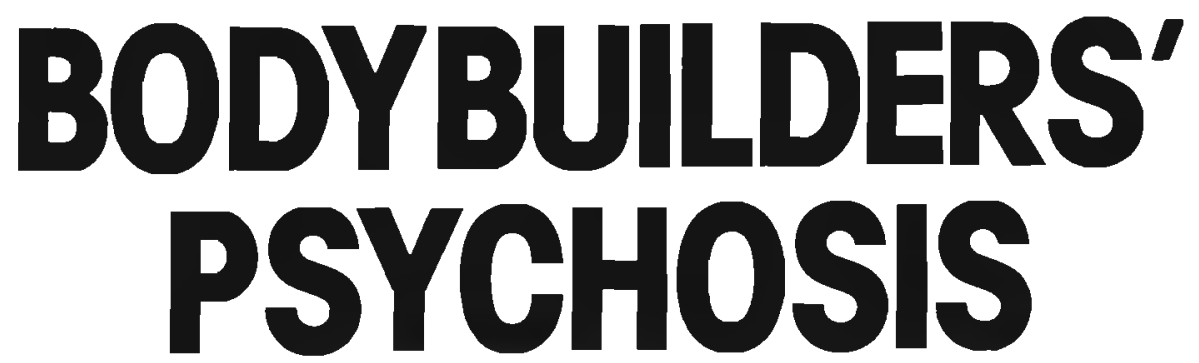

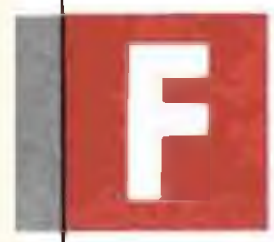

urther warning of the hazards of misuse of anabolic steroids by athletes is given by Drs Harrison Pope and David Katz of McLean Hospital and Harvard Medical School in Massachusetts. They treated two men requiring hospital admission for psychosis apparently related to steroid use One was a 22-year-old construction worker who took two eight-week courses of methandrostenolone for bodybuilding.

The second was a 40-year-old man with idiopathic impotence who developed major depression with delusions and hallucinations after being prescribed

\section{"After the second course he developed severe depressive symptoms which lifted after several months but were followed by prominent paranoid and religious delusions."}

methyltestosterone for two weeks. Neither patient had any serious psychopathology before this episode and no medical or neuroendocrine abnor malities were found. Both responded well to neuroleptics and have remained psychiatrically normal for more than two years follow up with no further steroid exposure

Intrigued by these cases, Drs Pope and
Katz interviewed 31 other anabolic sterold users recruited through advertisements in gymnasia: three had psychotic symptoms including hallucinations and delusions and at least four others had 'subthreshold' psychosis in cluding paranoid jealousy and grandiose beliefs. In addition, four met criteria for manic episodes while taking steroids and five had major depres sion.None of the subjects described comparable behaviour when not using steroids. Such cases show that in addition to well-described medical effects of anabolic steroids there may be seri. ous psychiatric effects which have so far been largely unexplored.

Lancet, 1987, Apr 11, i,863. low back pain in certain sports, the most common cause is overuse and resultant strains or sprains of the paravertebral muscles and ligaments. Such injuries cause acute pain and spasm, which sometımes do not ap pear for 24 hours or longer. Diagnosis is based on history, ruling out of sys. temic maladies, physical examination, and, if necessary, supplemental tests such as $x$-rays, myelograms, and bone scans. Treatment of low back pain due to overuse is, sequentially, bed rest and ice for 24 to 36 hours, heat and massage, analgesics as needed, and a lumbosacral support until flexion and strengthening exercises have returned the damaged part to normal.

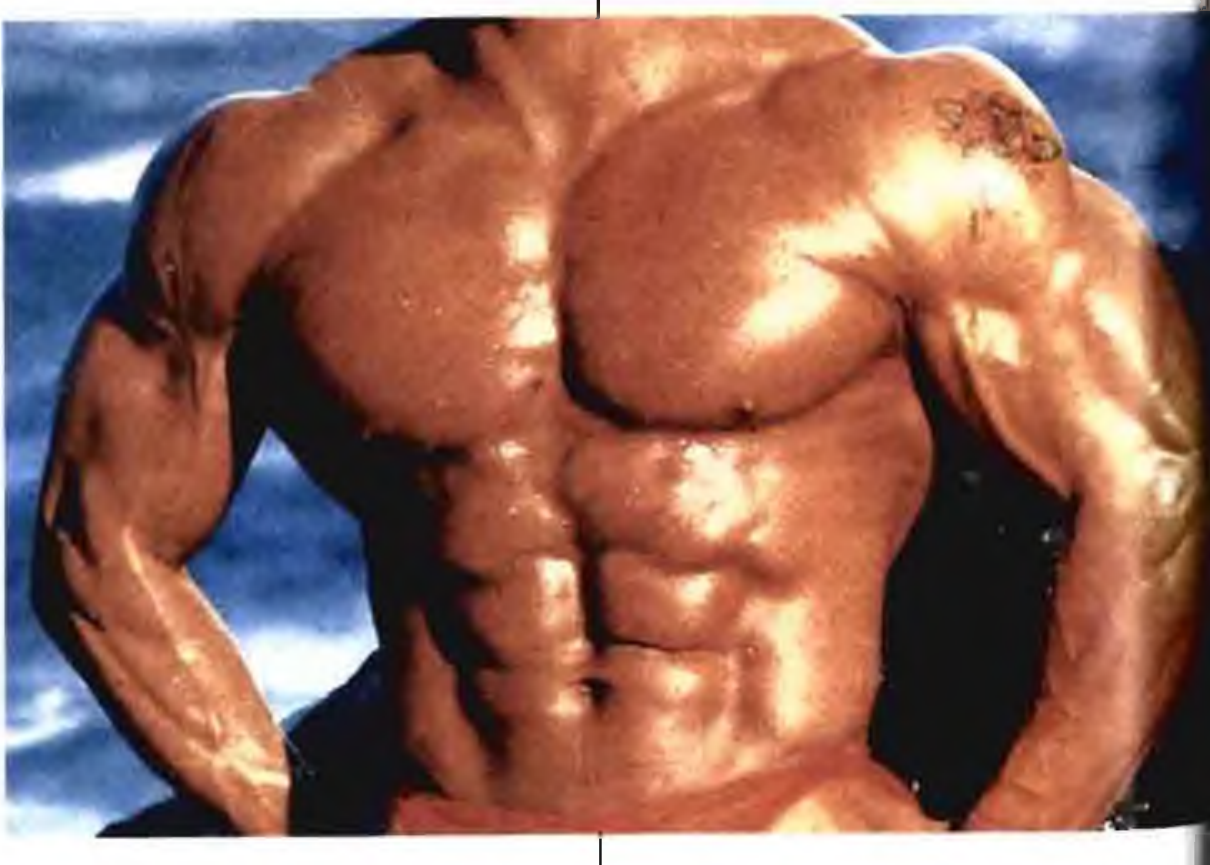

Acknowledgement

Medical News Tribune Jun 25, 1987

\section{George D. Rovere, MD}

Low back pain in seasoned athletes is not common, but when present it can limit participation. While direct blows or hyperlordotic positions can cause

\section{Reference}

The Physician and Sportsmedicine vol 15 , No. 1, January 87 
omrades TortureTrack by CAROLYN MCGIBBON

Research on runners could provide a new way of boosting performances in the Comrades Marathon by reducing body temperature and cutting out some of the gruelling agony of the $87-\mathrm{km}$ race. The research - which is a world first is still in its infancy, and critics have called for more comprehensive tests and controls before the results are accepted.

But early tests show that cramps, nausea, vomiting, diarrhoea and kidney problems - which make the Durban to Pietermaritzburg route a torture track - are linked to poisons, called endotoxins, released into the bloodstream from the gut after strenuous exercise

Tests carried out in the medical tent at last year's comra des, showed that more than 80 per cent of runners in the survey had very high endotoxin levels.

Antibodies fight the endotoxins, and research from Natal Medical School shows that hard training is a natural way of increasing the antibodies. But runners eager for boosted perfor. mances may be tempted to inject themselves with
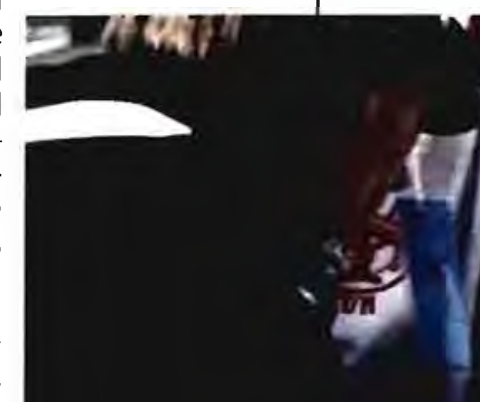

"When a runner is exhausted, he needs more blood sent to his muscles and so the blood supply is shunted from the gut. As a result, the barrier that stops endotoxins from entering the blood is broken down and the endotoxins come streaming out." body temperature shot up, making the runner more tired. Poor circulation led to cramps and kidney problems, he said. The basic treatment for kidney failure - which killed one Comrades Marathon runner last year - was to give intravenous fluids, which would have the effect of flushing endotoxins out of the system, he said.

Professor Brock-Utne suggested that in the future runners could be tested if they were unsure whether they would be able to complete the course Their antibody levels could give an indication of how fit they were People with very low antibodies might then be advised not to run, he said. Comrades doctor John Godlonton said he had strong reservations about draw- antibodies manufactured by the Blood Bank.

This could cause ethical problems for Comrades organisers who are battling to keep the sport clean. Runners are already subject to tests by the SA Amateur Athletics Union, but it would be difficult to prove whether runners are injecting themselves with antibodies. Mr Danie Malan, chairman of the SAAAU medical committee, said no road runner had been tested positively for drugs, and "blood doping" was unknown in South Africa.

Professor John Brock-Utne of the Physiology Department at Natal University, who headed the endotoxin research team said: "We have shown that high endotoxins can cause nausea, vomiting and diarrhoea. This may be circumven-

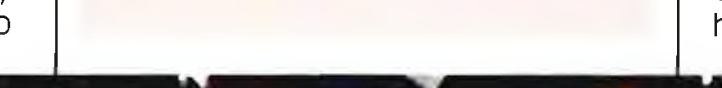




\author{
Exercises to Prevent and Treat Low Back Pain
}

1. Pelvic Tilt Lie on your back with knees bent, feet flat on the floor, and arms at your sides. Tighten your stomach muscles and flat. ten the small of your back agaınst the floor. without pushing down with the legs. Hold for five seconds, then slowly relax.

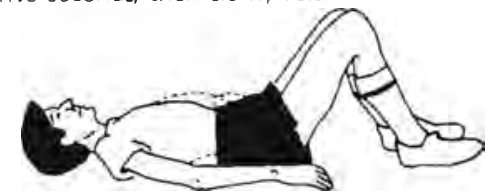

2. Knee to Shoulder. Starting in the same position as for the pelvic tilc, grasp your right knee and gently pull it toward your right shoul. der. Return to the starting position and repeat with the left leg Aiternate legs

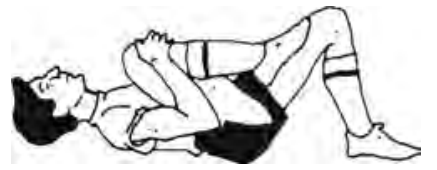

3. Double knee to chest. Starting in the same position as for the pelvic tilt, use your nands to pull your right leg close to your chest. and then pull the left leg even with the right Grasp both knees and pull them toward your shoulders Let the knees return to arm's length and repeat.

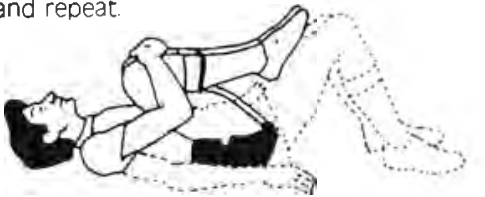

4. Partlai SIt-up. Do the pelvic tilt, and while notding this position, curl your head and shoul. ders up and forward. Hold briefly. Return slow. ly to the starting position

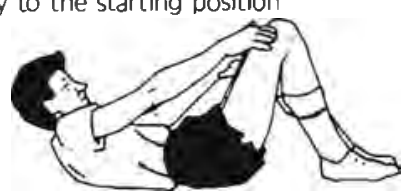

5. Hamstring stretch. From the same start. ing position as for the pelvic tilt, oring one knee to vour chest and then straighten the leg vertically, stretching the heel toward the celling. You should feel the stretch behind your knee Bend the knee and return the leg to the starting position. Repear with the other leg

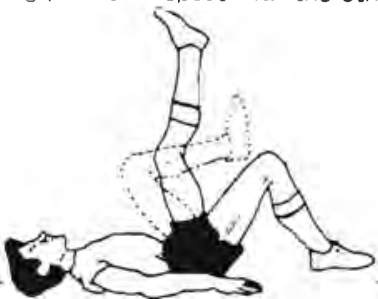

6. Rotational Sit-up. Do the pelvic tilt and. while keeping your hips flat, rotate your up. per body so that the weight rests on the left shoulder Then, curl your head and shouiders upward, raising your right shoulder nigher than the left Hold briefly before returning to the starting position. Rotate your upper body to the right and repeat the movement, this time rasing the left shoulder higher than the right.

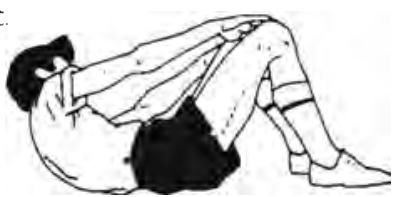

7. Cat and camel. On your hands and knees, relax your abdomen and let your back sag downward Then tighten your stomach mus. cles and arch your back Repear

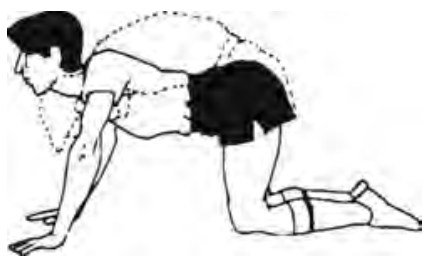

8. Trunk Flexion, Prone. Starting on your hands and knees, tuck in your chın and arch your back upward, and then slowly sit back on your heels while letting your shoulders drop to the floor Relax Return to the starting po sition, keepıng stomach tight and back arched Repear.

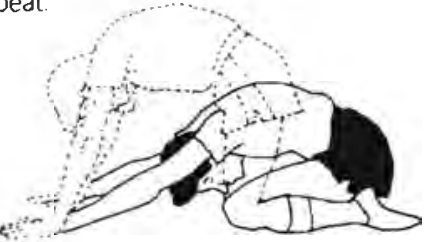

9. Trunk Flexion, Seated. Sitting near the edge of a chair, spread legs apart and cross arms over your chest Be sure the chair will not slip backward or tip. Tuck your chin and slowly curl your trunk downward. Relax. Uncurl slow. ly into an upright position. rassing your head last

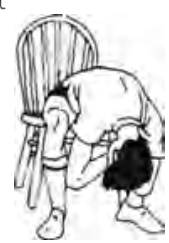

Reference

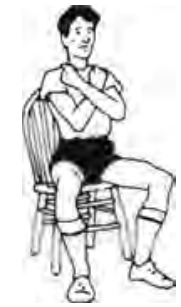

Vol 15, No. 1, Januarv 87.

The physician and sports medicine.

\section{CONTINUED FROM PAGE 10}

Bester takes Uitra

Manlead

Lynnwood drive-in theatre and the clos. ing date for entries is November 2.

All Vasbyters who complete the race within 10hourswill receive amedal, track suit badge and certificate.

Thenextcompulsoryevent after thecy. clechallenge is the Hansa Duzi in January. in which Ultra Man entrants can paddie either single or $\mathrm{K} 2$ canoes.

The other compulsory events are the $160 \mathrm{~km}$ Sunday Times/Leppın Iron Man triathlon in Februaryand the $87 \mathrm{~km}$ Comrades marathon next June

Theoverall winner will receive agold medalandR10,000, with a medaland R1,000 for the others in the top 10 and R2,000 and a medal for the winner of each compulsory event

In addition there will be a medal and R1,000 for the first master (over 40) and a medal and $R 2,000$ for the top woman. FOR FURTHER INFORMATION CONTACT MICHELLE REIMERS AT SPORTS INTER. NATIONAL ON (011) 883-3333.

\section{ULTRAMAN RESULTS FOR} JSE MARATHON - 1st 20

\begin{tabular}{|c|c|c|}
\hline POS & NAME & $\begin{array}{l}\text { TOTAL } \\
\text { POINTS }\end{array}$ \\
\hline 1. & Nicolaas Bester & 100.00 \\
\hline 2 & Piet Mare & 92.38 \\
\hline 3 & Danny Biggs & 85.99 \\
\hline 4. & Graeme Pope-Ellis & 85.22 \\
\hline 5. & Pierrede Jager & 84.72 \\
\hline 6. & Phillip van Tonder & 84.02 \\
\hline 7 & RogerZipo & 83.13 \\
\hline 8. & Philip Demosthenous & 82.72 \\
\hline 9 & GeoffMatthews & 81.77 \\
\hline 10. & Kennethpoole & 81.77 \\
\hline 11. & Stephen Rehoock & 81.15 \\
\hline 12. & Norrie Williamson & 81.14 \\
\hline 13. & Didier Entressangle & 8090 \\
\hline 14. & Lochilochner & 80.82 \\
\hline 15. & Richard Marshall & 80.13 \\
\hline 16. & Jako van Heerden & 80.09 \\
\hline 17. & Eddie King & 80.02 \\
\hline 18 & Roelof du Toit & 79.88 \\
\hline 19. & Martın Wood & 79.13 \\
\hline 20. & Colin Cooper & 78.70 \\
\hline & WOMEN'SRESULTS & \\
\hline 1. & Pricilla Carlisle & 68.76 \\
\hline 2. & Sally Luckhoff & 59.30 \\
\hline 3. & Sandra Niemandt & 48.22 \\
\hline
\end{tabular}




\section{RUGBY

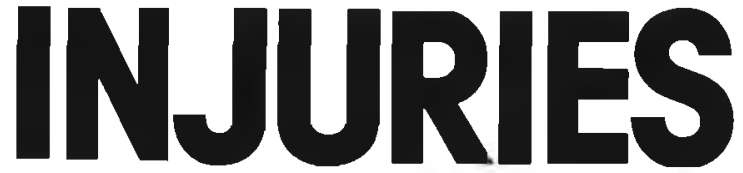 \\ AND

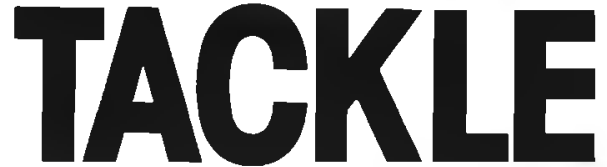

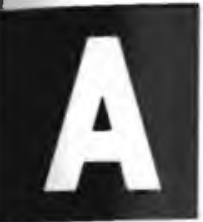

Forum for our readers

This forum invites our readers to air their views on any subject related to sport and sports medicine.

We welcome your ideas, criticisms, contribution, etc. Address correspondence to: The Managing Editor, Commedica, PO Box 3909, Randburg 2125.

The Editor

Sports Journal

Rugby injuries and Tackle

Dear Sir

With regard to the above I wish to state that the incidence can be reduced, possibly to 0,5\% by:

1) Proper coaching techniques with emphasis on basics - how to fall how to tackle. how to scrum etc.

2) Change the tackle law

a) For schools - a TACKLER may only aim for the body area, between the shoulder (under the axilla) and the hips (on or above circumference bounded by symphysis pubis, anterior and posterior superior iliac spines)

b) The tackle will not involve throwing the ball carrier to ground The ball carrier will only have to be held in this position and he must then release, pass or kick the ball.

In other words - it would be a modified form of touch rugby.

If, however the ball carrier is thrown to ground, it will not be against the rules. By changing the tackle law as above, I feel that (even for senior rugby) it will:1) Speed up the game

2) It will cut down on rucks, Mauls Pile ups - thereby reducing injuries

3) Reduce injuries in general and es pecially knee and ankie injuries. i have written a similar letter to or Danie Craven who mentioned that such changes may take ages via the Intemational Rugby Board.

But, why shouldn't we, as Medical sports people, have it pushed through earlier even on a local experimental basis. Yours faithfully

Dr S Ger

PS. The playing time should be divided into 4 sessions with 3 min breaks between each session.

\section{Reply to Dr Ger's letter} The Rugby Injury

Refering to Dr Selwyn Ger's letter regarding rugby injuries, it remains encouraging to note that some physicians

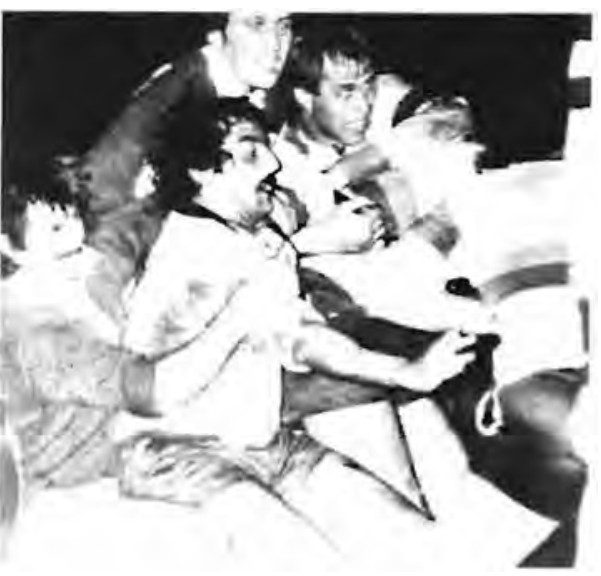

remain concerned about rugby injuries and are willing to make suggestions regarding possible ways of reducing these injuries.

It is important that Dr Ger forwards detailed proposals to the Medical Committee of the S.A. Rugby Board. Possible law changes will also involve discus sions with the particular governing bodies like the S.A. Schools Rugby ASsociation in this case before a well motivated proposal can be presented to the S.A. Rugby Board for further consideration.

All attempts must be made to introduce law changes without changing the basic spirit and the game itself. Dr Hugo

Chairman: Medical Committee Rugby Board

\section{SPORTS INJURY REPRINT SERVICE}

Sports Injuries occur as a result of physical activities carried out either for general recreational purposes or with more professional goals in mind. They may be caused by accidents or by overuse, and they do not necessarily differ from injuries sustained in non-sporting activities.

Most sports injuries are minor and would not prevent the average athlete from continuing his daily work, but as more and more people become seriously committed to sporting activities continuing daily work is no longer the only consideration. The injury needs to be treated effectively so that leisure activity can also be resumed at the earliest opportunity.

Progress in diagnosis and treatment is making rapid strides in the field of sports medicine, and to keep doctors abreast of recent developments Ciba Ceigy have introduced a SPORTS INJU RY REPRINT SERVICE. This service searches medical publications for the most recent articles dealing with Sports Medicine and makes them available to interested doctors

Careful and planned rehabilitation is essential after an injury. Ciba-Geigy, as leaders in the field of antirheumatic and Sports Medicine, awarded a grant to the National Sports Research and Training Institute to promote scientific sport research and training.

Doctors who wish to receive reprints of articles dealing with Sports Medicine on a regular basis, ond/or would like more information on the Ciba-Ceigy Sport injury Rehabilitation Programme should write to:

CIBA-GEIGY (PTY) LIMITED

PHARMACEUTICAL DIVISION

PO BOX 92

ISANDO

1600

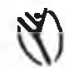




\section{NATIONAL SYMPOSIUM}

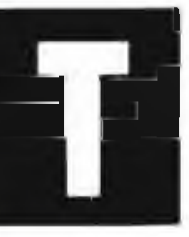

heme: Drugs \& Sport Participation. Date: To be advised Venue Sports Centre - University of Pretoria

As a result of the nega tive publicity concerning sport participation and the use of drugs as well as the ignorance and health dangers of the incorrect use of illegal drugs, the Institute for Sport Research and Training at the University of Pretoria have decided to hold a national symposium in order to develop sound perspective in this regard. Experts in this field have been invited to present papers covering various topical issues regarding this subject.

The programme is as follows:

The Techniques of Testing - by Dr $P$ vd. Merwe (UOVS)

Medical Aspects of Ergogenics \& other Chemical Compounds - by Dr D. v. Velden (University of Stellenbosch) Biochemistry of lllegal Drugs - by Professor F. Terblanche (University of Zululand)

Ethical Aspects - by Professor Hannes Botha (University of Pretoria)

The Use of Anabolic Steroids from a health point of view - by Professor R. van Rooyen (University of Pretoria) Scientific-accepted Training Methods for the Development of Strength - by Dr $\mathrm{N}$ de Bruyn (University of Pretoria) Diet and Strength Development - by Ms Mieke Faber (National Medical Council - Tygerberg Hospital

Invitations will be sent out to coaches, physiologists, parents, General Practioners and members of the pharmaceutical industry. For further information please contact Gert Potgieter or Petra Talijaard at tel. no (012) 342-2150.

\section{CME course in sports Medicine - Durban 1987}

The S.A. Sports Medical Association is organising a continued Sports Medical Educational Course in Durban from the 7th to 9th of April 1988. This will be held in the Elangeni Hotel. Emphasis will be placed in various medical and

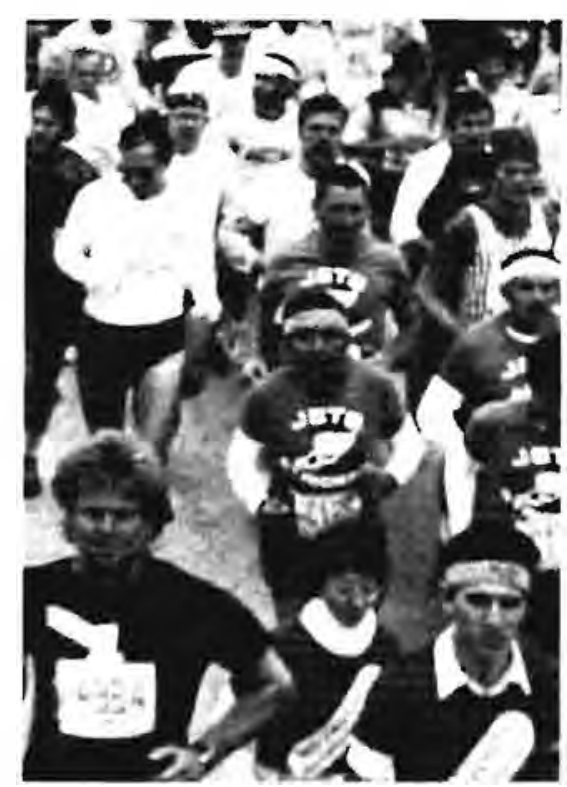

physiological aspects in the runner and include training and conditioning as well as methods of treating running injuries. Forms of intent will be sent to all members of the S.A. Sports Medical Association and other interested bodies.

Further information will be published in Sports Medicine Journal Vol 2 No 4 in November. However early registra. tions and queries can be directed to the:

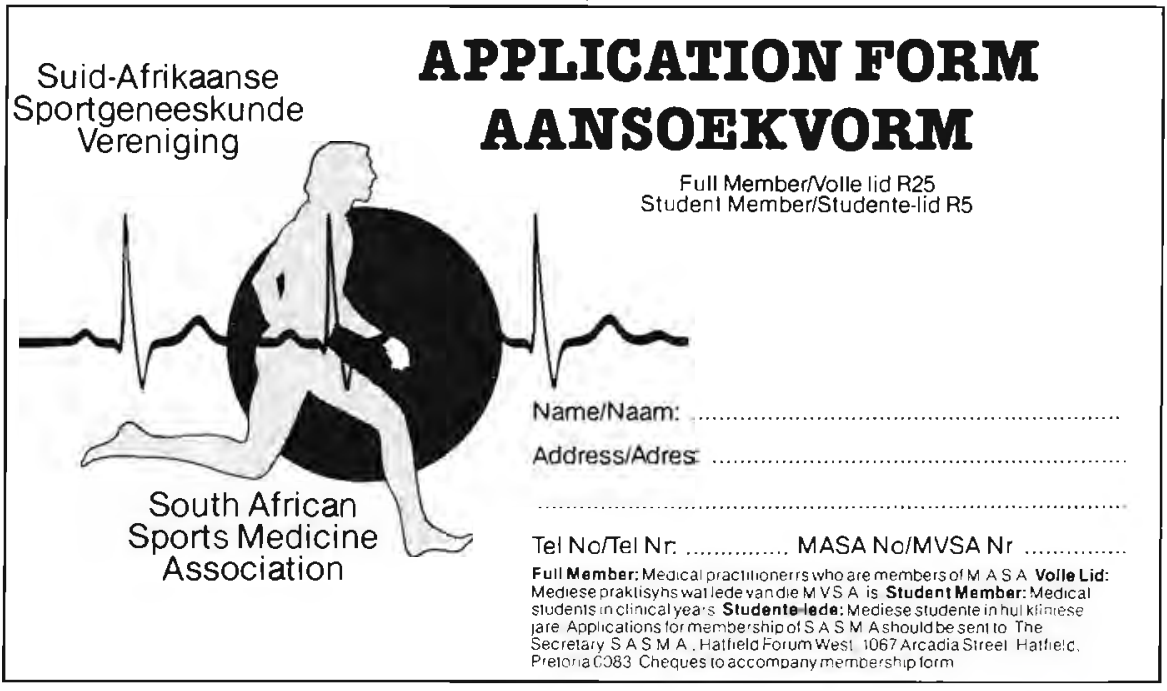

Organising Committee SASMA

Hatfield Forum West

2nd Floor 1067 Arcadia Street

Hatfield

Pretoria 0083

Tel No. 012 - 43-5594/5/6

\section{In Memoriam}

It is with great regret that we learned of the passing away of Dr Etricia Prins100 in July this year, just five months after having diagnosed her own illness - a rare form of leukaemia.

Etricia was a medical doctor working on a master's degree in sports medicine (biokinetics) at the University of Pretoria. She was the secretary of SASMA since April 1987 and an active member of the association since its inception four years ago

She played a major role in improving communication and co-operation between Physiotherapists and Medical Practitioners involved in sports medicine and has been actively involved in the expansion of sports medicine in South Africa.

She will be sorely missed by all SASMA members and we would like to take this opportunity to extend our sincere sympathy to her husband and family.

will be placed in various medical and 